\title{
The contribution of coral reef-derived dimethyl sulfide to aerosol burden over the Great Barrier Reef: a modelling study
}

Sonya L. Fiddes ${ }^{1,2, *}$, Matthew T. Woodhouse ${ }^{2}$, Steve Utembe ${ }^{3}$, Robyn Schofield ${ }^{4}$, Joel Alroe ${ }^{5}$, Scott D. Chambers $^{6}$, Luke Cravigan ${ }^{5}$, Erin Dunne ${ }^{2}$, Ruhi S. Humphries ${ }^{2}$, Graham Johnson ${ }^{5}$, Melita D. Keywood ${ }^{2}$, Todd P. Lane ${ }^{4}$, Branka Miljevic ${ }^{5}$, Yuko Omori ${ }^{7,8}$, Zoran Ristovski ${ }^{5}$, Paul Selleck ${ }^{2}$, Hilton B. Swan ${ }^{9}$, Hiroshi Tanimoto ${ }^{8}$, Jason P. Ward ${ }^{2}$, and Alistair G. Williams ${ }^{6}$

${ }^{1}$ ARC Centre of Excellence for Climate System Science and the Australian-German Climate and Energy College, University of Melbourne, Australia

${ }^{2}$ Climate Science Centre, Oceans and Atmosphere, Commonwealth Scientific and Industrial Research Organisation, Australia

${ }^{3}$ Environmental Protection Authority Victoria, Australia

${ }^{4}$ ARC Centre of Excellence for Climate Extremes, University of Melbourne, Australia

${ }^{5}$ International Laboratory for Air Quality and Health, School of Earth and Atmospheric Sciences, Queensland University of Technology, Australia

${ }^{6}$ Australian Nuclear Science and Technology Organisation, Lucas Heights, New South Wales, Australia

${ }^{7}$ Faculty of Life and Environmental Sciences, University of Tsukuba, Japan

${ }^{8}$ Earth System Division, National Institute for Environmental Studies, Tsukuba, Japan

${ }^{9}$ Faculty of Science and Engineering, Southern Cross University, Australia

*Now at the Australian Antarctic Program Partnership, Institute of Marine and Antarctic Studies, University of Tasmania, Australia

Correspondence: Sonya Fiddes (sonya.fiddes@utas.edu.au)

\begin{abstract}
Coral reefs have been found to produce the sulfur compound dimethyl sulfide (DMS), a climatically relevant aerosol precursor predominantly associated with phytoplankton. Until recently, the role of coral reef-derived DMS within the climate system had not been quantified. A study preceding the present work found that DMS produced by corals had negligible longterm climatic forcing at the global-regional scale. However, at sub-daily time scales more typically associated with aerosol and cloud formation, the influence of coral reef-derived DMS on local aerosol radiative effects remains unquantified. The Weather Research and Forecasting - chemistry model (WRF-Chem) has been used in this work to study the role of coral reef-derived DMS at sub-daily time scales for the first time. WRF-Chem was run to coincide with an October 2016 field campaign over the Great Barrier Reef, Queensland, Australia, against which the model was evaluated. After updating the DMS surface water climatology, the model reproduced DMS and sulfur concentrations well. The inclusion of coral reef-derived DMS resulted in no significant change in sulfate aerosol mass or total aerosol number. Subsequently, no direct or indirect aerosol effects were detected. The results suggest that the co-location of the Great Barrier Reef with significant anthropogenic aerosol sources along the Queensland coast prevents coral reef derived-aerosol from having a modulating influence on local aerosol burdens in the current climate.
\end{abstract}




\section{Introduction}

Dimethyl sulfide (DMS) is an important precursor gas for aerosol formation. DMS is produced predominantly by marine organisms such as algae, phytoplankton and corals. Once emitted, atmospheric DMS (DMS ${ }_{a}$ ) has a lifetime of approximately 1-2 days (Korhonen et al., 2008; Kloster et al., 2006; Khan et al., 2016) and is primarily oxidised by hydroxyl (OH) and nitrate $\left(\mathrm{NO}_{3}\right)$ radicals. Oxidation of DMS produces methanesulfonic acid (MSA), dimethyl-sulfoxide (DMSO) and ultimately $\mathrm{SO}_{2}$, which then oxidise further into $\mathrm{H}_{2} \mathrm{SO}_{4} \cdot \mathrm{H}_{2} \mathrm{SO}_{4}$ can subsequently condense onto pre-existing particles (heterogeneous nucleation) or, if in sufficiently high atmospheric concentration and in the absence of pre-existing surfaces, $\mathrm{H}_{2} \mathrm{SO}_{4}$ can nucleate into new particles (homogeneous nucleation). In the free troposphere, cooler temperatures, higher supersaturation, and fewer pre-existing particles can provide ideal conditions for aerosol precursor gases to undergo homogeneous nucleation. In the boundary layer however, the specific conditions needed for nucleation occur far less frequently. ? estimate in the marine boundary layer, only $10 \%$ of low level cloud CCN (cloud condensation nuclei) are created in boundary layer nucleation, compared to $45 \%$ in the free troposphere and subsequently entrained to lower levels.

At the global scale DMS plays an important role in global climate modulation via direct (McCormick and Ludwig, 1967) and indirect aerosol effects (Twomey, 1974; Pincus and Baker, 1994; Albrecht, 1989; Warner, 1968). Thomas et al. (2010), Mahajan et al. (2015) and Fiddes et al. (2018) each found global DMS to have a radiative effect of $-2.03 \mathrm{~W} \mathrm{~m}^{-2},-1.79 \mathrm{~W} \mathrm{~m}^{-2}$ and $-1.7 \mathrm{Wm}^{-2}$ at the top of the atmosphere respectively.

Coral reef ecosystems are an unaccounted for source of DMS (Broadbent et al., 2002; Broadbent and Jones, 2004; Jones and Trevena, 2005; Jones et al., 2007; Burdett et al., 2015; Deschaseaux et al., 2019; Jackson et al., 2020b). Many of these studies suggest that the contribution of DMS from coral reefs is a significant source of marine aerosol and may have an impact on local climate. Links to coral reef-derived DMS, aerosol formation, cloud cover and/or sea surface temperatures (SSTs) have been made by a range of observational studies (Modini et al., 2009; Deschaseaux et al., 2012; Leahy et al., 2013; Swan et al., 2017; Jones et al., 2017; Cropp et al., 2018; Jackson et al., 2018, 2020a). In particular, during a campaign on the Great Barrier Reef (GBR) Modini et al. (2009) describe several instances of boundary layer nucleation events during periods of clean marine air mass. These events resulted in peaks in nucleation mode aerosol number concentrations associated with sulfate and organic aerosol. While acknowledging that the precursor gases could have a continental origin, Modini et al. (2009) suggest that they are more likely from marine sources. Furthermore, the authors attribute one particularly strong event to precursor gases specifically produced by the GBR. Jackson et al. (2018) show a positive correlation between the satellite derived aerosol optical depth (AOD) and SSTs and irradiance, suggesting the source of sulfur coming from the GBR to be the cause of this result. Similarly, Cropp et al. (2018) also find a positive correlation between satellite derived AOD and coral stress indices taking into account irradiance, tidal activity, and water clarity. Jackson et al. (2020b) further find a significant link of satellite derived AOD to in-situ $\mathrm{DMS}_{a}$ during periods of calm in daylight hours, suggesting that coral reef production of DMS $\mathrm{D}_{a}$ resulted in condensational growth of sulfate aerosol. Furthermore, Jackson et al. (2020b) again report significant correlations of AOD to irradiance and SSTs, citing this as possible evidence for a bioregulatory feedback, which has also been suggested in previous studies (Jones, 2013; Jones et al., 2017; Cropp et al., 2018). 
A bioregulatory feedback between coral and DMS would be an example of the CLAW (Charlson, Andreae, Warren and Lovelock) hypothesis (Charlson et al., 1987), which proposes that marine organisms produce more DMS when stressed, which when released into the atmosphere undergoes oxidation and participates in direct and indirect aerosol radiative effects by contributing to the formation of sulfate aerosol. Thus by releasing DMS, organisms are able to cool their environment. However, the studies suggesting that coral reefs participate in bioregulatory feedback cannot fully take into account the complexity of the DMS-climate system and its significant non-linearities. Studies that rely on observational products cannot easily separate the many influences on aerosol loading found in complex coastal regions, for example the influence of sea spray aerosol, continental air masses or intrusions from the free troposphere.

Fiddes et al. (2021) provided the first global modelling study to quantify the climatic influence of coral reefs. This study found that most coral reefs globally were too small to have any effect on aerosol burdens with the exception of those around the Maritime Continent and Australian region. However, although coral reefs in the Australasian region were found to contribute to nucleation and Aitken mode aerosol, little evidence of a long-term climatic impact could be found over the regions. The results from both Fiddes et al. (2021) and Fiddes et al. (2018) further suggest that regions with large aerosol loading, from either anthropogenic or natural aerosol sources, are unlikely to be sensitive to very small changes in DMS concentrations.

While there have been numerous studies quantifying the global influence of DMS on climate (as discussed in Fiddes et al., 2018), this is not the case for impacts of DMS on regional climate, let alone coral reef-derived DMS. Regional modelling studies of DMS in the atmosphere and its interactions with local weather and climate are few. DMS has been included in regional climate models (such as the Weather Research and Forecasting model coupled to chemistry, WRF-Chem) since the early 2000s with the incorporation of the Georgia Tech/Goddard Global Ozone Chemistry Aerosol Radiation and Transport (GOCART) scheme (Chin et al., 2000). However DMS is rarely the topic of interest, with little attention being paid to the effects of DMS on aerosol, clouds, and climate. This gap in research is concerning given that DMS has been found in observational studies to explain a significant part of aerosol variability, especially in clean marine areas (Vallina et al., 2006; Korhonen et al., 2008).

One exception is the major campaign VAMOS (Variability of the American Monsoon Systems) Ocean-Cloud-AtmosphereLand Study Regional Experiment (VOCALS), which made extensive measurements in the Southeast Pacific stratocumulus deck (off the coast of Chile and Peru). Whilst DMS was not the main focus, Yang et al. (2011) and Saide et al. (2012) evaluate DMS in WRF-Chem (V3.3) relative to the VOCALS observations. Both these studies suggest that the DMS flux (flux $D M S$ ) is overestimated in the model when compared to ship based measurements. The overestimation of flux $D M S$ resulted in a high bias in $\mathrm{DMS}_{a}$ concentrations. Whilst these overestimations of flux $D M S$ were considerable, both Yang et al. and Saide et al.'s focus was not on sensitivity testing of DMS, and hence both studies stop short of evaluating how DMS alone may affect aerosol-cloud interaction.

More recently, Muñiz-Unamunzaga et al. (2018) show the importance of including marine halogens and DMS on air quality monitoring for a large coastal city (Los Angeles). The authors note that these inclusions can decrease ozone and nitrogen dioxide levels and can cause large changes in oxidants $\left(\mathrm{OH}, \mathrm{HO}_{2}\right.$ and $\left.\mathrm{NO}_{3}\right)$ and the composition of particulate matter. Studies such as this highlight the importance of DMS not only on clean marine areas, such as those explored in VOCALS, but also in 
more polluted urban environments. However, Muñiz-Unamunzaga et al. (2018) provide no evaluation of the impact of DMS itself on the local climate.

In this study, we aim to explore the extent to which coral reef-derived DMS can influence local aerosol burdens over the Great Barrier Reef. We do this by evaluating the ability of WRF-Chem to simulate DMS processes and analysing what the impact of including an additional coral reef source of DMS is on aerosol processes. We evaluate WRF-Chem against observations from a major field campaign undertaken in the austral spring of 2016: 'GBR as a significant source of climatically relevant aerosol particles', nicknamed 'Reef to Rainforest' (R2R). The model setup, experiment design and field campaign details are provided in Section 2, while the results of this work are provided in Section 3 and summarised by Section 4.

\section{Methods}

\subsection{WRF-Chem configuration}

WRF-Chem simulations were run for the period: 1st October 2016, at 1200UTC to the 25th October 2016, 1200UTC, to align with the R2R campaign. Two nested domains (one way) were chosen (see Figure 1). The outer domain (D01) covers the majority of the Australian continent and the Coral Sea and is run at a $27 \mathrm{~km}$ horizontal grid spacing with a 120 second time step. The inner domain (D02) runs at a $9 \mathrm{~km}$ horizontal grid spacing with a 60 second time step and covers the state of Queensland and the majority of the Great Barrier Reef. All simulations have 41 vertical levels in the troposphere (up to 20.4 $\mathrm{km}$ ), including 11 levels below $1 \mathrm{~km}$, and produce hourly output for each domain.

All WRF-Chem simulations have been meteorologically nudged to provide the best comparison to the R2R field campaign and to ensure that the responses found in the model are attributable to the DMS surface water concentration (DMS $\left.\mathrm{D}_{w}\right)$ perturbations and not internal model variability. The Australian Bureau of Meteorology (BoM) Atmospheric high-resolution Regional Reanalysis for Australia - Regional domain (BARRA-R) has been used to provide initial conditions and to perform nudging at six hourly intervals (Su et al., 2018). Nudging has been applied to temperature and water vapour above the planetary boundary layer and to horizontal wind above vertical level 19 (approximately $3 \mathrm{~km}$ ).

The model was restarted every 4 days (ingesting the previous day's chemical conditions), with a 12 hour spin up thrown out. The chemical boundary and initial conditions are provided by the Model for Ozone and Related Chemical Tracers (MOZART4, Emmons et al., 2010). WRF-Chem maps aerosol mass and number to the eight simulated bin sizes (Fast et al., 2006) from the bulk aerosol mass provided by MOZART-4, representing the Aitken mode through to the accumulation mode. A full description of the chemistry, aerosol and physics setup for these simulations can be found in Appendix A.

\subsection{DMS climatologies}

The default $\mathrm{DMS}_{w}$ climatology provided by WRF-Chem is the outdated Kettle and Andreae (2000) climatology on a $1 \times 1.25^{\circ}$ grid. The climatology used here is the updated Lana et al. (2011) DMS ${ }_{w}$ (referred to henceforth as the L11 climatology). The interpolation performed by WRF-Chem (via Prep-Chem) was deemed unsatisfactory (creating unphysical patterns around the 
coastlines and generally a very coarse interpolation). For this reason, the L11 climatology for October was interpolated to each WRF-Chem domain using the python (v3.5) basemap bilinear interpolation, overriding the default WRF-Chem DMS $_{w}$ climatology. Further smoothing around the coastlines was performed. All fields that pass through Prep-Chem underwent the same interpolation to a higher resolution for consistency.

After initial testing, it was found that simulations using $\mathrm{L} 11$ overestimated $\mathrm{DMS}_{w}$ in comparison to observations taken during the R2R campaign (this finding will be described in Section 3). For this reason, a scaled $\mathrm{DMS}_{w}$ climatology was created, where L11 was divided by 2.8 to match the average $\mathrm{DMS}_{w}$ observations taken during the R2R campaign. The scaled climatology is referred to as L11S henceforth.

To examine the impact of coral reef-derived DMS, a new source of $\mathrm{DMS}_{w}$ was added to the L11S climatology. The coral reef source was determined by using the areal fraction of coral reefs per WRF-Chem grid box to add a weighted $50 \mathrm{nM}$ of $\mathrm{DMS}_{w}$, matching that of the global analysis performed in Fiddes et al. (2021). The $50 \mathrm{nM}$ value was chosen as a high range estimate in order to maximise any potential signal and response. In reality, this source varies considerably with time (Jones et al., 2007, eg. up to as much as $54 \mathrm{nM}$ ), but is likely much smaller. The coral reef $\mathrm{DMS}_{w}$ source added to the L11S climatology is referred to as L11SCR and is shown by the coloured contours in Figure 1 along side the R2R DMS ${ }_{w}$ observations.

\subsection{Experiment setup}

Three simulations are analysed in this study. The first simulation uses the L11 climatology (and hence will be referred to as the L11 simulation), with no biomass burning or dust and with the Gong et al. (1997) sea salt emissions. While this climatology is not the default $\mathrm{DMS}_{w}$ climatology in WRF-Chem, it is the most up to date, warranting its evaluation. The second simulation uses the L11S DMS $w$ climatology scaled to the ship observations (and subsequently referred to as the L11S simulation). In addition, L11S uses the Fuentes et al. (2010) sea salt parameterisation which now includes an organic aerosol component that is excluded under the Gong et al. (1997) parameterisation. Biomass and dust emissions are also included. The third simulation uses the L11SCR DMS ${ }_{w}$ climatology and otherwise the same setup as L11S, to examine if coral reef-derived DMS ${ }_{w}$ plays a role in aerosol characteristics over the region.

\subsection{Observations and evaluation methods}

The R2R field campaign took place on two platforms, the first on board the CSIRO Marine National Facility RV Investigator (RVI) which navigated a path around the GBR from the 28th September - 22nd October 2016. The ship track is given in Figure 1. The second platform used in R2R was the Atmospheric Integrated Research Facility for Boundaries and Oxidative Experiments (AIRBOX) mobile atmospheric chemistry lab, stationed at Mission Beach, QLD from the 20th September to the 16th October 2016. The position of AIRBOX is given in Figure 1. Note that in both domains, WRF-Chem considers this grid point as ocean (the container was $<50 \mathrm{~m}$ from the shoreline). Observations collected both on the RVI and at AIRBOX comprised measurements of meteorology and atmospheric chemical and aerosol composition. These observations aimed to capture each step of the DMS cycle over the GBR for the first time. A list of observations used in this study from the R2R 
campaign can be found in the Appendix Tables B1 and B2 as well as a brief description of how the data was collected and processed. All observations are available from the relevant institutions upon request.

To compare the estimated flux ${ }_{D M S}$ from the model and observations we used the Liss and Merlivat (1986) parameterisation given modelled and observed $\mathrm{DMS}_{w}$, SSTs and wind fields. To evaluate sulfate aerosol, particle size bins were linearly interpolated to observed particle sizes, assuming aerosol bins are internally mixed. In order to determine periods of time in which the RVI observations were contaminated by ship exhaust, the hourly black carbon concentrations needed to be above $50 \mathrm{ng} \mathrm{m}^{-3}$ and the wind direction relative to the ship was $>120$ and $<240$ degrees. Any time stamp within \pm five minutes of meeting these two criteria were also flagged. Air-masses were considered to have marine origins if radon concentrations were below $300 \mathrm{mBq} \mathrm{cm}^{-3}$.

To aid the airmass characterisation, the Hybrid Single Particle Lagrangian Integrated Trajectory Model (HYSPLIT) was used to perform back trajectories (Draxler and Hess, 1997, 1998). The National Centers for Environmental Prediction (NCEP) Global Data Assimilation System (GDAS) 0.5 degree product was used to produce the back trajectories, where vertical motion was calculated using the model vertical velocity. Initial height was set at $100 \mathrm{~m}$ and the trajectories were run for 72 hours, every two hours.

For the WRF-Chem evaluation, time series comparisons, correlations and a bias factor metric have been used, evaluating equivalent model fields to the observations taken during R2R. Evaluation focused on domain two. The Normalised Mean Bias Factor (NMBF, Yu et al., 2006) is used. The NMBF is a symmetric metric, i.e. negative biases are not bound by zero, and remains viable when measured values are much smaller than model values. This metric is an improvement on other model performance metrics, as described by Yu et al. (2006). To ensure clarity of this metric across both positive and negative biases, the NMBF has been converted into a bias factor $(\mathrm{BF})$ by adding 1 if $\mathrm{NMBF}<0$, or subtracting 1 if $\mathrm{NMBF}>1$. Correlation analysis has been performed using Spearman's rank correlation methods (Wilks, 2011). This method is a non-parametric test that quantifies the monotonicity of the relationship between two variables.

\section{Results}

\subsection{Surface water DMS and the resulting sea-air flux}

Figure 2 shows the timeseries of $\mathrm{DMS}_{w}$, wind speed and the resultant flux ${ }_{D M S}$ for the three WRF-Chem simulations and the RVI observations. In Figure 2a, the effect of scaling the L11 DMS ${ }_{w}$ climatology can clearly be seen, where L11S represents a more realistic value for the GBR region with a BF of 1.02 compared to L11 of 2.74 . While the L11 climatology is the most up to date gridded data set of $\mathrm{DMS}_{w}$ available (although is not the default climatology for WRF-Chem), we can see that for this region it significantly overestimates DMS. This result highlights that much greater sampling of $\mathrm{DMS}_{w}$ variability over space and time is required, especially in regional studies.

Figure $2 \mathrm{~b}$ shows that overall the model predicts wind speed along the RVI path well, with L11S having a NMBF of 1.06, and a correlation coefficient of $\mathrm{R}=0.87$ to the observations. The diurnal cycle is also well captured (not shown) although the model tends to underestimate and delay the peak wind speed. This is attributed to the poor simulation of the sea breeze structure 
(results not shown). Some model skill may be attributed to the fact that RVI observations are assimilated into the BARRA reanalysis product used to nudge the model, although we also note that model winds are free running below $3 \mathrm{~km}$. Comparison of wind roses (not shown) indicates that the model has a bias of winds from the south-east. This bias reflects the predominant large scale flow over the area for this time of year.

Wind speed is a key factor in the Liss and Merlivat (1986) flux parameterisation. An estimate of the flux $D M S$ along the RVI track is shown in Figure 2c. Here we can see that despite the model's constant $\mathrm{DMS}_{w}$, it is able to do a comparatively good job representing the average flux ${ }_{D M S}$, with a BF of 1.21 for L11S, compared to 2.32 for L11. This skill is predominantly due to the well captured marine wind speeds discussed above. Visually, the L11S flux ${ }_{D M S}$ timeseries appears to follow that of the observations relatively closely, although with a weak $\mathrm{R}$ value of 0.24 and underestimated variance $\left(\right.$ where $\sigma_{L 11 S}=2.77, \sigma_{O b s}$ $=3.11$ ), likely due to the constant $\mathrm{DMS}_{w}$.

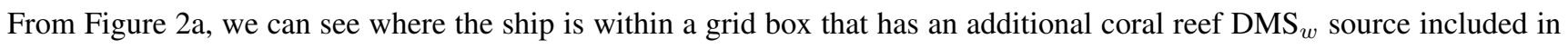
L11SCR. The corresponding flux ${ }_{D M S}$ is in general much larger than what was observed although we recognise that the ship did not measure directly over coral reefs. Nevertheless, this is a clear demonstration of how additional coral reef DMS is influencing the flux $D M S$ and should subsequently influence $\mathrm{DMS}_{a}$.

\subsection{Atmospheric DMS and sulfate aerosol mass}

Figure $3 \mathrm{a}$ and $\mathrm{b}$ shows $\mathrm{DMS}_{a}$ from the RVI and at AIRBOX. The average at both sites is moderately well captured. For the RVI, the BF for L11S compared to the observations is 1.29, while at AIRBOX this is 1.42. Weak (negative) and insignificant correlations are found for both locations. The poorer performance of the model at AIRBOX may be due to the complexity of the location on the coast. However, the weak and negative correlations suggest that the model is missing an important aspect of $\mathrm{DMS}_{a}$ variability, likely caused by the constant $\mathrm{DMS}_{w}$ field or perhaps missing chemical sinks. While WRF-Chem has more complex DMS chemistry compared to other chemical models, comprising 30 DMS oxidation pathway reactions, it is possible that it is still missing important reactions. For example, the importance of DMS removal by $\mathrm{BrO}$ or $\mathrm{Cl}_{2}$ has been highlighted in the literature (Breider et al., 2010; Khan et al., 2016; Muñiz-Unamunzaga et al., 2018). Specifically, Khan et al. (2016) note that without these inclusions, the variability of $\mathrm{DMS}_{a}$ is not well modelled.

Nevertheless, significant improvement can be seen in $\mathrm{DMS}_{a}$ in the L11S simulations compared to the standard L11 simulation. The addition of coral reef $\mathrm{DMS}_{w}$ has made a small difference in $\mathrm{DMS}_{a}$ when near reef regions. However, the significant changes to $\mathrm{DMS}_{w}$ between L11, L11S and L11SCR have not had a significant impact on the sulfate aerosol mass, shown in Figure $3 \mathrm{c}$ and $\mathrm{d}$.

For L11S, over the entire timeseries, the model underestimates the observations of sulfate aerosol mass by approximately $0.11 \mu \mathrm{g} \mathrm{m}^{-3}$, with a BF of 1.3. A moderate correlation of $\mathrm{R}=0.46$ suggests that the model is capturing some of the observed trends and variability. For AIRBOX, the underestimation of the observations by L11 increases to $0.16 \mu \mathrm{g} \mathrm{m}^{-3}$ and the BF is 1.43. In addition, a statistically significant negative relationship is found between the two timeseries $(\mathrm{R}=-0.16)$. This is likely due to a number of local sulfate sources observed by AIRBOX that were not included in the model, for example, vehicle emissions, that impact that variability of the timeseries. 
Importantly, we note that reducing $\mathrm{DMS}_{w}$ by approximately $65 \%$ between $\mathrm{L} 11$ and L11S results in a decrease of only $10 \%$ in total surface sulfate aerosol mass along the RVI track. It is possible that this is because L11S also included biomass burning, while $\mathrm{L} 11$ did not. The mean difference of $\mathrm{SO}_{4}{ }^{2-}$ surface concentration for L11 and L11S over the entire RVI timeseries is $-0.039 \mu \mathrm{g} \mathrm{m}^{-3}$. When periods of contaminated air (airmasses that contained high levels of black carbon, terrestrial influence or were flagged for other reasons) are filtered out of the calculations, the difference between L11 and L11S was $-0.049 \mu \mathrm{g} \mathrm{m}^{-3}$, or a $-15 \%$ change. The difference between the filtered and unfiltered means suggests that the inclusion of biomass burning has offset the sulfate reduction caused by $\mathrm{DMS}_{w}$ only marginally (by about 5\%). Nevertheless, these results imply that DMS only plays a small role in the sulfate aerosol burden over the GBR.

\subsection{Terrestrial airmass influence}

Figure 4a shows the time series of radon and black carbon (for both the RVI and L11S), the mean wind direction in the model and three sets of HYSPLIT trajectories over Stations 3.1, 3.2 and 4. It is clear from the radon timeseries that over the campaign, the ship did not encounter what could be considered clean marine air often (defined as periods below $300 \mathrm{mBq} \mathrm{cm}^{-3}$ ), although we note that exposed coral reef atolls are also a source of radon. The radon time series is coloured by the exhaust contamination flag and indicates that there were even fewer occasions in which conditions uninfluenced by ship exhaust (shown by the green colours) or terrestrial air mass were measured.

Comparing the RVI black carbon to the L11S concentrations, where ship exhaust from the RVI is not included, we can see some agreement in periods of terrestrial airmass (eg. between stations 3.1 and 3.2). While the L11S black carbon levels are lower than what was measured, the mean of of $0.07 \mu \mathrm{g} \mathrm{m}^{-3}$ over the time period shown is above that of which was considered clean in this study $\left(0.05 \mu \mathrm{g} \mathrm{m}^{-3}\right)$ also implying a predominant terrestrial influence.

In Figure 4b, south easterly surface winds are shown to prevail, although some bias in the day to day wind direction was found compared to the RVI (not shown). Looking at this map, one may expect that this period did comprise clean marine airmasses, and, as an example, this time of year was in part chosen due to this prevailing wind direction. However, as the 72 hour HYSPLIT back trajectories in Figure 4c-e show, despite the wind coming from the south east, much of the time, this airmass had actually recirculated over the Australian continent and spent only a partial time over the ocean. The dominance of terrestrial airmass during the R2R campaign was also demonstrated by Chen et al. (2019), where much of the airmass measured at AIRBOX had strong terrestrial influence, with signatures of biomass burning.

In addition to unfavourable synoptic conditions, one such cause of a lack of clean marine periods is the influence of sealand breeze coupling. Over coastal-marine regions recycling of airmasses over the land and ocean can occur and have far reaching impacts. For example, a sea-land breeze circulation up to $150 \mathrm{~km}$ offshore under favourable conditions during the R2R campaign was detected in previous (unpublished) WRF simulations (personal communication C. Vincnet). Similarly, sea-land coupling was also observed at AIRBOX (not shown). This circulation between land and ocean can lead to terrestrial airmasses extending far offshore. 


\subsection{Dominant anthropogenic sources of sulfur}

Now we consider not just how DMS has changed over the RVI track or at AIRBOX, but how it has changed over the entire WRF domain, and in particular over coral reef regions. A vertical transect of $\mathrm{DMS}_{a}$ and the surface mean for the entire domain is shown in Figure 5a and b. In this figure, the source of coral reef $\mathrm{DMS}_{a}$ is clearly evident in the boundary layer (c) and being blown with the prevailing winds at the surface in (d). Over the entire domain, at the surface, a significant increase in DMS $a$ of $0.003 \mathrm{ppb}$ is found, approximately $12 \%$, with a mean increase of $40 \%$ found over coral reef grid points. These significant increases in $\mathrm{DMS}_{a}$ however, do not result in significant change in sulfate aerosol mass, as found along the RVI track and at AIRBOX.

Figures $6 \mathrm{a}$ and $\mathrm{b}$ show the vertical transect and surface mean of total sulfate aerosol mass (including in-cloud sulfate aerosol). These two plots clearly demonstrate that anthropogenic emissions represent a significant source of sulfate aerosol (among other species) for the GBR region. In Figure 6a, over the Gladstone coal fire power station (brown triangle), a dominant plume in sulfate aerosol can be seen, while in Figure 6b, numerous plumes, that align with known power generators, can be seen.

Figure, $6 \mathrm{c}$ and $\mathrm{d}$ indicate no coherent change in total sulfate aerosol mass that could be robustly attributed to the inclusion of coral reef-derived DMS. The surface mean change between L11S and L11SCR over the entire domain is $0.0018 \mu \mathrm{g} \mathrm{m}^{-3}$, or a change of $0.38 \%$. Directly over coral reef grid points, an increase of $0.47 \%$ was found.

\subsection{Nucleation pathways of coral reef-derived DMS}

The prevalence of anthropogenic sulfur and the abundance of pre-existing particles suggests that the small addition of sulfate from DMS is unlikely to participate in new particle formation in the boundary layer. Rather, it is more likely that coral reefderived $\mathrm{H}_{2} \mathrm{SO}_{4}$ would condense onto pre-existing particles, growing their mass. Below, we analyse column integrals of aerosol number and mass in the free troposphere and boundary layer to test this hypothesis.

Figure 7 shows the transect of the boundary layer (left) and free troposphere (right) total column sulfate mass and aerosol number for the bins representing Aitken and accumulation mode aerosol. We suggest that regions where the changes along the transects in the number and mass co-vary are likely due to internal model variability, rather than changes in the $\mathrm{DMS}_{a}$ field. In the larger bins (Figure 7e-j), this appears to be the case in most locations. However, in the smaller bins (Figure 7a-d), some instances where the mass has changed independently of the number are found.

In Figure 7a and c, the total boundary layer total column sulfate mass has increased in some areas, while the number has not. These increases may be evidence of condensational growth. Importantly we note that the regions over which the increase in mass occur are not co-located with coral reefs, but may be due to advected $\mathrm{DMS}_{a}$ and its oxidation products.

In the free troposphere, new particle formation is far more likely to occur. Examining the smallest bin size (Figure 7b) however, no clear evidence of the coral reef-derived sulfuric acid participating in new particle formation is found. Rather, directly over coral reefs, a relatively large decrease in sulfate aerosol mass is found, with a lesser reduction in particle number concentration. These decreases may suggest that the coral reef-derived precursors have grown existing small sized particles, causing them to shift into larger bin sizes. On average over the transects for the remaining bin sizes, increases in free tropospheric sul- 
fate mass was found, accompanied by decreases in number (keeping in mind that these changes are insignificant and less than $1 \%$ ). This may further suggest greater coagulation rates, reducing the number, while increasing the mass. However, due to the very small and insignificant changes found, we have low confidence that these results are caused directly by coral reef-derived DMS as opposed to model noise.

While locally, changes in sulfate mass in some cases appear to be up to 5\%, on average the changes over the transects in either the boundary layer or free troposphere are less than $1 \%$. Furthermore, the largest signals from coral reef-derived DMS appear to occur in the smallest size aerosol, with little discernible change in the larger aerosol sizes that are of greater climatic relevance. Examination of changes in cloud condensation nuclei (not shown) confirm this and indicate that the very small addition of sulfate by corals is unlikely to have any direct or indirect aerosol effects over the GBR region. Further investigation of these aerosol effects has been carried out, and no significant changes in clear sky radiation, total radiation, cloud droplet number, liquid water path, cloud fraction or precipitation were found.

\section{Conclusions}

Coral reefs as an unaccounted-for source of DMS have gained attention over recent years, with numerous observational studies suggesting they play an important and even regulatory role in local climate (Jones, 2013; Hopkins et al., 2016; Jones et al., 2017; Cropp et al., 2018; Jackson et al., 2018, 2020b). While Fiddes et al. (2021) in a global modelling study found that coral reef derived DMS over the Maritime Continent and Australian region had little impact on long-term climate, no regional-scale modelling has been performed prior to this present study. This is particularly important if we are considering temporal and spatial resolutions relevant to bioregulatory feedbacks. In this work, we have evaluated the ability of WRF-Chem to simulate DMS and sulfur processes and tested the sensitivity of these processes to perturbations in $\mathrm{DMS}_{w}$, with a particular focus on coral reef-derived DMS.

We find that, compared to observations taken during the R2R campaign, the Lana et al. (2011) climatology significantly overestimates $\mathrm{DMS}_{w}$ and required reduction by $65 \%$ to be of a similar magnitude. This finding adds to a growing argument of a need for an updated and if possible, time-varying (beyond the fixed monthly climatology), $\mathrm{DMS}_{w}$ climatology (e.g. as suggested in Green and Hatton, 2014). Furthermore, this finding demonstrates that greater attention needs to be paid to the $\mathrm{DMS}_{w}$ climatology within modelling systems, highlighted by the fact that the default WRF-chem climatology is the out of date Kettle and Andreae (2000) climatology.

With a DMS ${ }_{w}$ field that aligns with observations, the Liss and Merlivat (1986) flux $D M S$ calculated from both observations and the model agree reasonably well in magnitude. This result is in part due to the well-captured marine wind speeds along the RVI track. Subsequently, $\mathrm{DMS}_{a}$ is also reasonably well captured, although overestimated, as is sulfate aerosol mass over the ship track. The Liss and Merlivat (1986) flux parameterisation is considered a conservative parameterisation compared to other methods which provide much larger fluxes (see Appendix for details). Hence the overestimation of $\mathrm{DMS}_{a}$ found here (despite matched $\mathrm{DMS}_{w}$ and well captured wind speeds) further suggests that Liss and Merlivat (1986) is the most realistic 
parameterisation for calculating the flux $x_{D M S}$. Nevertheless, this evaluation gives us confidence that the model is able to capture the key processes in the DMS-aerosol system.

By comparing simulations with the original Lana et al. (2011) $\mathrm{DMS}_{w}$ climatology to the scaled climatology, we find that DMS plays only a small role in sulfate aerosol burdens over the GBR. For a $65 \%$ reduction in $\mathrm{DMS}_{w}$, a subsequent $67 \%$ reduction in $\mathrm{DMS}_{a}$ and a 10-15\% reduction in sulfate aerosol mass was found at the surface. Examination of the background meteorological conditions indicate that influence from terrestrial airmasses occurred for the majority of the R2R campaign, which was broadly reflected in the WRF-Chem model. Furthermore, we suggest that local anthropogenic sources of sulfur from fossil fuel power generation is likely to have a strong influence over the GBR airmass due to proximity, interaction of the sea breeze and synoptic conditions. We recommend further observational studies are carried out to confirm if this is the case for different times of year. Additionally, we note that major coral bleaching events occurred in the summer prior to this field campaign. While the coral reefs south of Cairns (the region of this campaign) were not as severely bleached, we cannot rule out an impact on the production of DMS by coral reefs due to this event.

These results suggest that much smaller changes in DMS from coral reefs are unlikely to have a large impact on the aerosol burden. We find that by adding in a source of coral reef DMS, the total sulfate aerosol mass increases by less than $1 \%$, while insignificant changes of a similar magnitude were found for the total aerosol number. Over the time period studied, no evidence of new particle formation was found, although condensational growth in boundary layer and free troposphere in the smallest aerosol bins may have occurred. No evidence of direct or indirect aerosol effects were found in response to these very small changes in aerosol mass and number.

Whether the lack of influence from coral reef-derived DMS on the local aerosol burden was a result of unfavourable synoptic conditions is difficult to assess. However, the close proximity of anthropogenic aerosol emissions to the inner GRB suggests that this region should not be considered a 'clean marine' environment unless under very specific conditions, therefore limiting the role that coral reef-derived DMS can play in aerosol formation and growth while these emissions continue. We suggest that the influence of anthropogenic aerosol is analysed in future work by exploring if an increase in ammonium was also found, associated with sulfate produced by a power station. While Modini et al. (2009) suggested that they had observed new particle formation in such 'clean marine' conditions, further work needs to be done to understand how often such conditions occur over the GBR before we can consider if these new particle formation events could have an influence on aerosol and weather.

This study indicates that it is more likely the small contribution of volatile sulfur compounds from the GBR contribute to aerosol growth via condensational pathways. While this is in agreement with the hypothesis presented in Jackson et al. (2020b), our results suggest that the growth in the smaller sized aerosol (Aitken mode) due to coral reef-derived DMS is still too small to have an impact on radiative or cloud processes. This finding is in agreement with the global simulation study described in Fiddes et al. (2021).

However, a limitation of WRF-Chem to be considered here is that the binned aerosol scheme only represents aerosol of Aitken mode sizes and larger. The DMS-climate cycle is in part dependant on nucleation sized aerosol, as found by Fiddes et al. (2018) and Fiddes et al. (2021), where nucleation in the free troposphere plays an important role. Parameterising the nucleation processes, rather than explicitly resolving nucleation mode aerosol may have a significant impact on the results, 
especially when considering the small increase in aerosol mass with no robust change in aerosol number found here. The implicit parameterisation of nucleation mode aerosol may hence help explain the low sensitivity of aerosol to changes in DMS. This suggestion supports that made by Zaveri et al. (2008) who note that the Wexler et al. (1994) homogeneous nucleation parameterisation used here underpredicts binary nucleation, while over predicting ternary nucleation in the boundary layer. An aerosol scheme that explicitly simulates smaller sized aerosol would be desirable for future studies.

A limitation of this study the nudged meteorology (every six hours), potentially limiting the ability of indirect aerosol effects to occur and any possible feedbacks. As shown in Fiddes et al. (2021), large differences can be found in aerosol-climate processes between nudged and free running simulations, although differentiating between model noise and a real signal is difficult. Furthermore, the four day restarts of WRF-Chem, despite ingesting the previous day's chemistry, appeared to impact total aerosol numbers, including CCN, which were found to be strongly constrained by this set-up choice. This impact has limited the analysis of these fields in this study. The restarts were not thought to impact the DMS processes, in part due to the lifetime of DMS in the atmosphere.

We suggest future studies should consider running both nudged and free simulations to ensure a full understanding of the aerosol-climate system. However, we do not expect that in a similar study to this, the results would be significantly changed in a free running simulation due to the very small changes in aerosol found in this work, the abundance of anthropogenic aerosol, and the fact that the meteorological nudging was not applied in the boundary layer.

While in the current climate, this study, in agreement with Fiddes et al. (2021), suggest that coral-reef derived DMS has only a minor influence on small sized (nucleation-Aitken mode) aerosol, we suggest future work focuses on what the influence may be under 'pristine' conditions. Planned work will target the 'clean marine' period identified in the R2R campaign and consider the downwind processes from the RVI to AIRBOX, where the airmass crosses coral reefs. As this work has shown, small increases in sulfate aerosol mass is found directly over coral reefs and how this evolves downwind is of interest. Of further interest, and perhaps yielding more significant results, would be a study conducted under pre- or post-industrial emissions conditions. Simulations such as this become particularly relevant if we consider a post-anthropogenic aerosol emissions world, in which coral reefs such as the Great Barrier Reef may already be extinct.

Code and data availability. RVI data including ship location, meteorology, black carbon and radon are available on the CSIRO Marlin Metadata System: https://www.cmar.csiro.au/data/trawler/. Remaining RVI and AIRBOX data will be submitted to PANGAEA in the near future, and in the mean time is available upon request. WRF-Chem namelists are avialable upon request and data can be made upon reasonable request. WRF-Chem analysis was performed using the wrf-python software package (Ladwig, 2017). 


\section{Appendix A: WRF-Chem Chemistry, aerosol and physics set-up}

\section{A1 Chemistry and aerosol}

The Carbon Bond Mechanism Z (CBMZ) chemical mechanism with aqueous chemistry and DMS is used in conjunction with the Model for Simulating Aerosol Interactions and Chemistry (MOSAIC) aerosol scheme. Dry deposition of gases and aerosol are turned on, as is wet scavenging (including convective wet scavenging). In-cloud chemistry, turbulent mixing and subgrid convective transport is also switched on. The FTUV (Fast Tropospheric Ultraviolet-Visible) photolysis scheme (Tie, 2003) is used.

MOSAIC represents aerosol via a sectional approach with eight discrete size bins. For each bin, the number and mass of particles are simulated: defined by the lower and upper limit of the dry particle diameter (Zaveri et al., 2008). Particle growth is calculated in a Lagrangian manner and transfer of particles between bins is calculated using a two-moment approach (Simmel and Wurzler, 2006). Coagulation of aerosol is calculated according to Jacobson et al. (1994). Homogeneous nucleation of $\mathrm{H}_{2} \mathrm{SO}_{4}-\mathrm{H}_{2} \mathrm{O}$ in MOSAIC is calculated via the Wexler et al. (1994) scheme. In MOSAIC, growth to Aitken mode particles is simulated implicitly as newly nucleated particle sizes are smaller than the smallest simulated aerosol size in the model. Heterogeneous nucleation in MOSAIC is partitioned into two schemes, treating condensation of non-volatile gases $\left(\mathrm{H}_{2} \mathrm{SO}_{4}\right.$ and methanesulfonic acid) and condensation and evaporation of semi-volatile gases $\left(\mathrm{HNO}_{3}, \mathrm{HCl}\right.$ and $\left.\mathrm{NH}_{3}\right)$ separately (Zaveri et al., 2008).

MOSAIC includes 11 specific aerosol species: sulfate $\left(\mathrm{SO}_{4}{ }^{2-}\right.$ and $\mathrm{HSO}_{4}{ }^{-}$), methanesulfonate, nitrate, chloride, carbonate, ammonium, sodium, calcium, black carbon, primary organic matter plus water, and treats other unspecified aerosol species as a lumped mass or through substitutions of equivalent species. Some gas phase species, including sulfuric acid and MSA, are allowed to partition to the particle phase. Atmospheric DMS chemistry is not a part of the CBMZ scheme, but was added with the development and coupling of MOSAIC (Zaveri et al., 2008). The DMS chemistry is based on that of Zaveri (1997) and includes 11 species and 30 reactions.

The Liss and Merlivat (1986) parameterisation is used to calculate the flux $\mathrm{DMSS}_{\mathrm{S}}$ emissions in WRF-Chem. As noted in Fiddes et al. (2018) and (Fiddes et al., 2021), the Liss and Merlivat (1986) parameterisation is considered a conservative method but is believed to be the most realistic (Vlahos and Monahan, 2009; Bell et al., 2017). Sea salt emissions are calculated online via either the Gong et al. (1997) parameterisation or the Fuentes et al. (2010) adaptation which includes a large addition of marine organic matter. All sea salt schemes have been found to overestimate sea salt emissions in WRF-Chem (eg. in Saide et al., 2012) and the Fuentes method especially so. Hence for simulations using the Fuentes high organics option, the sea salt emission was halved, as was the sea salt mass within the boundary and initial conditions.

Dust emissions are calculated via the Shao et al. (2011) scheme. Wet deposition of dust has been turned on and follows the Jung and Shao (2006) method. For daily biomass burning emissions, fire location data is provided by FIRMS (Fire Information for Resource Management System) via the MODIS (Moderate Resolution Imaging Spectroradiometer) Collection 6 platform operated by NASA and available from https://earthdata.nasa.gov/firms. The Brazilian Biomass Burning scheme (Longo et al., 2010) calculates the respective emissions and plume rise at daily resolution. Biogenic emissions are calculated online using the 
Guenther scheme (Guenther et al., 1994; Simpson et al., 1995). Anthropogenic emissions are prescribed from the Emissions Database for Global Atmospheric Research (EDGAR) V4.2, available at https://edgar.jrc.ec.europa.eu/ (European Commission Joint Research Centre and Netherlands Environmental Assessment Agency, 2012). Aircraft and volcanic emissions are not included.

\section{A2 Physics}

All simulations use the Morrison double moment cloud microphysics scheme (Morrison et al., 2008). The RRTMG (Rapid Radiative Transfer Model for General circulation models) model for longwave and shortwave radiation is used (Iacono et al., 2008), including the Monte Carlo Independent Column Approximation method for random cloud overlap (Barker et al., 2003).

415 Cumulus parameterisation was performed using the Grell 3D scheme, similar to the Grell-Devenyi Ensemble Scheme (Grell and Dévényi, 2002). In addition, cumulus radiation effects are switched on, allowing interaction of the radiation scheme and parameterised convective clouds (Gustafson et al., 2007). Cloud fractions are calculated using the Xu and Randall (1996) method, while cumulus and aerosol radiative feedbacks are permitted. Aerosol optical properties (Mie calculations) are approximated using the volume averaging method. The Noah Land Surface Model is used, with soil temperature and moisture in four layers, fractional snow cover and frozen soil physics (Chen and Dudhia, 2002). The boundary layer scheme used is the Mellor-Yamada-Janjic scheme (Janjić, 1994) operating in conjunction with the surface layer physics scheme, Eta (Janjic, 1996).

In WRF-Chem, with the chemistry and physics options described above, aerosol direct and indirect effects are permitted via the radiative, photolysis and cloud microphysical schemes. For direct aerosol effects, the size, number and composition of aerosol and aerosol water, refractive indices of aerosol types (based on literature) and the Mie calculations (Bohren and Huffman, 1998) update the AOD, the single scattering albedo and the asymmetry factor used in the RRTGM radiation scheme. Aerosol water has a large impact, and hence the relative humidity must also be considered when direct effects are being examined. In this work, water vapour has been nudged to the BARRA reanalysis, hence should not change significantly between experiments.

430 For indirect aerosol effects, the CCN number and composition is used to calculate the CDN in aerosol activation modules (Abdul-Razzak and Ghan, 2000, 2002). Activation depends on the composition and size of the particle (i.e. their hygroscopic properties), as well as the vertical and turbulent velocities of the air mass. First, second and semi indirect effects are calculated between both the chemistry and microphysics modules.

\section{Appendix B: Field observation methods}

\section{B1 DMS fields}

$\mathrm{DMS}_{w}$ observations were taken by the RVI for the duration of the voyage. Seawater samples (from between 0-5 $\mathrm{m}$ depth) were pumped through to the wet chemistry laboratory as part of the ship's routine underway measurements every minute. For 
Table B1. List of RVI observations used in the WRF-Chem evaluation, the institute responsible for data collection and processing, details on the instrument used and literature relevant to the data processing methods

\begin{tabular}{llll}
\hline Field & Institute & Instrument & Methods* \\
\hline DMS $_{\mathrm{w}}$ & NIES/University of Tsukuba & GC-2010-FPD \& EI-PTRMS & $\begin{array}{l}\text { Omori et al. (2013, 2017); } \\
\text { Kameyama et al. (2009) }\end{array}$ \\
$\mathrm{DMS}_{\mathrm{a}}$ & CSIRO & PTR-MS & NA \\
$\mathrm{SO}_{4}{ }^{-}$ & QUT/CSIRO & ACSM & Fröhlich et al. (2013) \\
Black Carbon & CSIRO/QUT & MAAP & Kanaya et al. (2013) \\
Radon & ANSTO/CSIRO & Radon detector & Chambers et al. (2021) \\
Wind speed \& direction & CSIRO & RM Young Wind Sensor & CSIRO (2016) \\
${ }^{*}$ Refer to in text data description for full methods & &
\end{tabular}

Table B2. List of AIRBOX observations used in the WRF-Chem evaluation, the institute responsible for data collection and processing, details on the instrument used and literature relevant to the data processing methods

\begin{tabular}{llll}
\hline Field & Institute & Instrument & Methods* \\
\hline DMS $_{\mathrm{a}}$ & Southern Cross University & GC-PFPD & Swan et al. (2015) \\
$\mathrm{SO}_{4}{ }^{2-}$ & QUT & AMS & Drewnick et al. (2005) \\
Black Carbon & CSIRO/QUT & MAAP & Kanaya et al. (2013) \\
Radon & ANSTO & Radon detector & Chambers et al. (2021) \\
Wind speed and direction & UoM & Thompson WS800 & NA \\
$*$ Refer to in text data description for full methods & &
\end{tabular}

the first half of the voyage (up until the 14th October) a Shimadzu gas chromatograph (GC-2010) (employing purge and trap gas chromatography) was used to detect $\mathrm{DMS}_{w}$. After the 14th October, due to competing demands for the GC, $\mathrm{DMS}_{w}$ was measured using an Equilibrator Inlet (EI) - Proton Transfer Reaction Mass Spectrometry (PTRMS) system (Kameyama et al., 2009; Omori et al., 2013, 2017). The seawater samples pumped by the ship system were flowed continuously into a 10-L glass equilibrator at $1 \mathrm{~L} \mathrm{~min}^{-1}$. Pure nitrogen flowed from the bottom to the upper outlet of the equilibrator at $120 \mathrm{sccm}$. Dissolved DMS was extracted into the $\mathrm{N}_{2}$ gas phase and introduced into the PTRMS (Ionicon Analytik GmbH, Innsbruck, Austria). The mass signal of DMS in the sample gas was obtained at 10-s integration at 1-min intervals. The $\mathrm{DMS}_{w}$ concentrations were calculated from concentrations in the sample gas extracted from the equilibrator with Henry's law constant (Kameyama et al., 2009). Comparison between the $\mathrm{DMS}_{w}$ observations taken by the two techniques show excellent agreement $\left(r^{2}=0.999\right)$ with high confidence $(p<0.001)$.

Accompanying the $\mathrm{DMS}_{w}$ measurements on board the RVI were $\mathrm{DMS}_{a}$ observations. A commercially available high sensitivity PTQRMS (Proton Transfer Quadrupole Reaction Mass Spectrometry; Ionicon Analytik GmbH, Innsbruck, Austria) was used to measure DMS ${ }_{a}$. The PTQRMS sampled via a $30 \mathrm{~m} 3 / 8$ inch ID PFA line with an inlet at the top of the mast on the foredeck $17 \mathrm{~m}$ above water level at a flow rate of $5 \mathrm{~L} \mathrm{~min}^{-1}$. The PTQRMS scanned masses from $\mathrm{m} / \mathrm{z} 21$ to 160 giving a full mass scan approximately every 10 minutes. DMS ${ }_{a}$ was measured at $\mathrm{m} / \mathrm{z} 63$ corresponding to the protonated parent molecule 
$\left(\mathrm{C}_{2} \mathrm{H}_{6} \mathrm{SH}^{+}\right)$. The PTQRMS drift tube was operated with an applied voltage of $600 \mathrm{~V}$, pressure of $2.2 \mathrm{mbar}(\mathrm{E} / \mathrm{N}=133 \mathrm{Td})$ and a average primary ion signal $(\mathrm{m} / \mathrm{z} 19)$ of $1.78 \mathrm{E}+07 \mathrm{cps}$. Data was filtered to remove periods of instrument instability. The PTQRMS was operated with a CSIRO custom built auxiliary system which controlled whether the PTQRMS sampled VOC-free air to determine instrument background, calibration gas to determine instrument response or ambient air. Zero air measurements occurred twice daily (1 - 2 AM and 1 - 2 PM UTC) and an interpolated zero signal was subtracted from the reported ambient and calibration measurement signals. Once per day (1400 to $1500 \mathrm{UTC}$ ) calibration measurements occurred

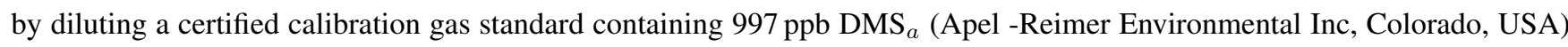
(stated accuracy $\pm 5 \%$ ) into VOC-free air. The instrument sensitivity to $\mathrm{DMS}_{a}$ was 11.3 normalised $\mathrm{cpsppb}^{-1}$ (rel. stdev $\pm 3 \%$ ). The minimum detectable limit (MDL) for a single $5 \mathrm{sec}$ measurement at $\mathrm{m} / \mathrm{z} 63\left(\mathrm{DMS}_{a}\right.$ ) was $0.029 \mathrm{ppb}$ determined using principles of ISO 6879 (ISO 1995). Values less than the MDL were removed.

At AIRBOX, DMS ${ }_{a}$ was measured using an automated gas chromatograph (GC) - pulsed flame photometric detector (PFPD). Measurements were taken every 20 minutes via an auto-sampler programmed to control the GC-PFPD. Full details on the

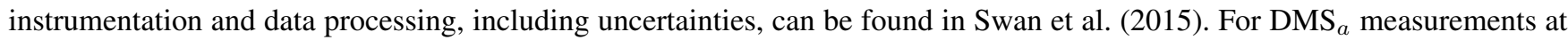
both platforms, the closest measurement within \pm 10 minutes to the hour was taken for comparison to the instantaneous hourly output from WRF-Chem.

\section{B2 Aerosol fields and radon}

Mass concentrations of black carbon (BC) at AIRBOX and on the RVI were obtained with a Thermo Scientific Model 5012 multi-angle absorption photometer (MAAP) and were used to help identify periods of air contaminated by ship exhaust. The MAAP sampled through a dedicated PM10 inlet, which was heated to minimise the influence of humidity on the BC measurements (Kanaya et al., 2013). Samples were acquired at $5 \mathrm{~s}$ time intervals and have been averaged to a 10-minute time resolution.

An Aerodyne compact Time-of-Flight Aerosol Mass Spectrometer (AMS) provided the non-refractory chemical composition of submicron aerosol at AIRBOX (Drewnick et al., 2005). The AMS sampled through a membrane dryer (Nafion MD-700) and a silica gel diffusion dryer which maintained sample relative humidities below $40 \%$. Daily measurements through a highperformance particle filter were used to calculate detection limits and correct for concentrations of background air species (Allan et al., 2004). Samples were averaged to 10-minute intervals. At this time resolution, the campaign-average detection limit was $5 \mathrm{ng} \mathrm{m}^{-3}$ for $\mathrm{SO}_{4}{ }^{2-}$.

On board the RVI, an Aerodyne Time of Flight Aerosol Chemical Speciation Monitor (ACSM) was used to obtain chemical composition of the non-refractory submicron aerosol. A full description of its design and operation is given in (Fröhlich et al., 2013). The ACSM inlet efficiency is at a maximum for vacuum aerodynamic diameters between 100-450 nm (Jayne et al., 2000; Liu et al., 2007) and therefore the composition measurements best represent accumulation mode aerosol. The AMS sampled through a membrane dryer (Nafion MD-700) which maintained sample relative humidities below $40 \%$. Samples were

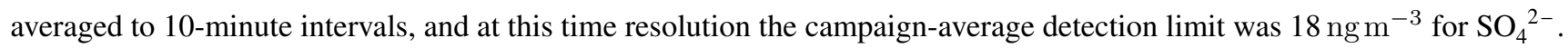


In addition, atmospheric radon-222 concentrations were measured both at AIRBOX and on the RVI using dual-flow-loop two-filter atmospheric radon detectors. Radon concentrations have been shown to be an accurate, independent measure of residual terrestrial influence within an airmass. Radon can subsequently be used to determine if an airmass has a marine or terrestrial origin, and can be satisfactorily used to detect 'baseline' airmass at locations such as Cape Grim, Tasmania, Ausralia (Chambers et al., 2021). While at Cape Grim, the baseline radon concentration is considered to be $30 \mathrm{mBq} \mathrm{cm}^{-3}$ or below, on board the RVI and at AIRBOX, terrestrial influence over the airmasses was much higher given their coastal location, prevailing wind directions and the fact that coral atolls, when exposed, are also a source of radon. For the RVI, a threshold of $300 \mathrm{mBq} \mathrm{cm}^{-3}$ was used to determine marine from terrestrial airmass. At AIRBOX no satisfactory threshold of radon could be determined to separate marine and terrestrial influences.

\section{B3 Wind}

On board the RVI, meteorological observations were taken as part of the routine observations. Observations are available at 5 or 10 second, or 5 minute intervals. The five minute interval has been used in this study. Where port and starboard observations were available, an average over the two was taken. These observations have been processed by the Marine National Facility and can be downloaded from the Marlin Metadata System (CSIRO, 2016), where more information can also be found. At AIRBOX, wind speed and direction, relative humidity, temperature and pressure observations were taken using a Thompson WS800 weather station. Observations were taken every 15 seconds. These observations have undergone basic quality control.

Author contributions. SF completed the WRF-Chem simulations, analysis and the initial draft of this manuscript. SU developed the initial model setup and provided advice as to the specific setup requirements of this study. MTW and SU helped guide the analysis and contributed significantly to the revisions of this manuscript. RS and TL provided advice and guidance on the direction of this study and contributed to the revisions of this manuscript. Remaining authors contributed observational data to this study and to the revisions of this manuscript.

Competing interests. The authors declare that they have no conflict of interest

Acknowledgements. This study and it's authors were supported by the ARC Discovery Project: Great Barrier Reef as a significant source of climatically relevant aerosol particles (DP150101649). SLF would like to thank P. J. Rayner and his research group for their helpful discussions and D. McConnell for providing the locations of power generators across Queensland. SLF was supported by the Australian

510 Research Council (ARC) Centre of Excellence for Climate System Science (CE110001028). TPL is supported by the Australian Research Council (ARC) Centre of Excellence for Climate Extremes (CE170100023). Financial support was given to HT and YO by Grant-in-Aid for Scientific Research (15H01732 and 17KK0016) from the Ministry of Education, Culture, Sports, Science and Technology, Japan. This research was undertaken with the assistance of resources and services from the National Computational Infrastructure (Project q90 and 
https://doi.org/10.5194/acp-2021-507

Preprint. Discussion started: 29 July 2021

(c) Author(s) 2021. CC BY 4.0 License.

(c) (i)

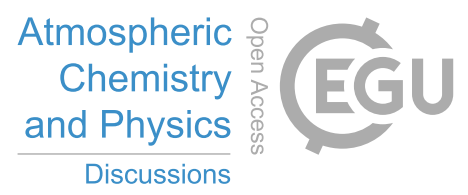

w40), which is supported by the Australian Government. SLF was supported by the Australian Government Research Training Program 515 Scholarship. 


\section{References}

Abdul-Razzak, H. and Ghan, S. J.: A parameterization of aerosol activation: 2. Multiple aerosol types, Journal of Geophysical Research: Atmospheres, 105, 6837-6844, https://doi.org/10.1029/1999JD901161, 2000.

Abdul-Razzak, H. and Ghan, S. J.: A parameterization of aerosol activation 3. Sectional representation, Journal of Geophysical Research Atmospheres, 107, 1-6, https://doi.org/10.1029/2001jd000483, 2002.

Albrecht, B. A.: Aerosols, cloud microphysics, and fractional cloudiness., Science, 245, 1227-1230, https://doi.org/10.1126/science.245.4923.1227, 1989.

Allan, J. D., Delia, A. E., Coe, H., Bower, K. N., Alfarra, M. R., Jimenez, J. L., Middlebrook, A. M., Drewnick, F., Onasch, T. B., Canagaratna, M. R., Jayne, J. T., and Worsnop, D. R.: A generalised method for the extraction of chemically resolved mass spectra from Aerodyne aerosol mass spectrometer data, Journal of Aerosol Science, 35, 909-922, https://doi.org/10.1016/j.jaerosci.2004.02.007, 2004.

Barker, H., Pincus, R., and Morcrette, J.-J.: The Monte-Carlo Independent Column Approximation: Application within large-scale models, in: Proceedings of the GCSS/ARM Workshop on the Representation of Cloud Systems in Large-Scale Models, p. 10, May 2002, Kananaskis, Alberta, Canada,, www.met.utah.edu/skrueger/gcss-2002/Extended-Abstracts.pdf, 2003.

Bell, T. G., Landwehr, S., Miller, S. D., De Bruyn, W. J., Callaghan, A. H., Scanlon, B., Ward, B., Yang, M., and Saltzman, E. S.: Estimation of bubble-mediated air-sea gas exchange from concurrent DMS and $\mathrm{CO} 2$ transfer velocities at intermediate-high wind speeds, Atmospheric Chemistry and Physics, 17, 9019-9033, https://doi.org/10.5194/acp-17-9019-2017, 2017.

Bohren, C. F. and Huffman, D. R.: Absorption and Scattering of Light by Small Particles, Wiley, Weinheim, Germany, https://doi.org/10.1002/9783527618156, 1998.

Breider, T. J., Chipperfield, M. P., Richards, N. A., Carslaw, K. S., Mann, G. W., and Spracklen, D. V.: Impact of BrO on dimethylsulfide in the remote marine boundary layer, Geophysical Research Letters, 37, 1-6, https://doi.org/10.1029/2009GL040868, 2010.

Broadbent, A., Jones, G. B., and Jones, R. J.: DMSP in Corals and Benthic Algae from the Great Barrier Reef, Estuarine, Coastal and Shelf Science, 55, 547-555, https://doi.org/10.1006/ecss.2002.1021, 2002.

Broadbent, A. D. and Jones, G. B.: DMS and DMSP in mucus ropes, coral mucus, surface films and sediment pore waters from coral reefs in the Great Barrier Reef, Marine and Freshwater Research, 55, 849-855, https://doi.org/10.1071/MF04114, 2004.

Burdett, H. L., Hatton, A. D., and Kamenos, N. A.: Coralline algae as a globally significant pool of marine dimethylated sulfur, Global Biogeochemical Cycles, 29, 1845-1853, https://doi.org/10.1002/2015GB005274, 2015.

Chambers, S. D., Williams, A. G., Crawford, J., Griffiths, A. D., Krummel, P. B., Steele, L. P., Law, R. M., van der Schoot, M. V., Galbally, I. E., and Molloy, S. B.: A radon-only technique for characterising atmospheric 'baseline' constituent concentrations at Cape Grim, Baseline Atmospheric Program (Australia) 2011-2013, 2021.

545 Charlson, R. J., Lovelock, J. E., Andreae, M. O., and Warren, S. G.: Oceanic phytoplankton, atmospheric sulphur, cloud albedo and climate, Nature, 326, 655-661, https://doi.org/10.1038/326655a0, 1987.

Chen, F. and Dudhia, J.: Coupling an Advanced Land Surface-Hydrology Model with the Penn State-NCAR MM5 Modeling System. Part II: Preliminary Model Validation, Monthly Weather Review, 129, 587-604, https://doi.org/10.1175/15200493(2001)129<0587:caalsh>2.0.co;2, 2002.

550 Chen, Z., Schofield, R., Rayner, P., Zhang, T., Liu, C., Vincent, C., Fiddes, S., Ryan, R. G., Alroe, J., Ristovski, Z. D., Humphries, R. S., Keywood, M. D., Ward, J., Paton-Walsh, C., Naylor, T., and Shu, X.: Characterization of aerosols over the Great Barrier Reef: The influence of transported continental sources, Science of The Total Environment, 690, 426-437, https://doi.org/10.1016/j.scitotenv.2019.07.007, 2019. 
Chin, M., Rood, R. B., Lin, S.-J., Müller, J.-F., and Thompson, A. M.: Atmospheric sulfur cycle simulated in the global model GOCART: Model description and global properties, Journal of Geophysical Research: Atmospheres, 105, 24671-24687, https://doi.org/10.1029/2000JD900384, 2000.

Cropp, R., Gabric, A., van Tran, D., Jones, G., Swan, H., and Butler, H.: Coral reef aerosol emissions in response to irradiance stress in the Great Barrier Reef, Australia, Ambio, https://doi.org/10.1007/s13280-018-1018-y, 2018.

CSIRO: RV Investigator Voyage IN2016_V05 Underway UWY Data, http://www.marlin.csiro.au/geonetwork/srv/eng/search\# !65e8e881-dafe-4ca5-8f8a-f69d83596523, 2016.

Deschaseaux, E., Jones, G. B., Miljevic, B., Ristovski, Z., and Swan, H.: Can corals form aerosol particles through volatile sulphur compound emissions?, in: Proceedings of the 12th International Coral Reef Symposium, edited by Yellowlees, D. and Hughes, T., James Cook University, Cairns, QLD, Australia, 2012.

Deschaseaux, E., Stoltenberg, L., Hrebien, V., Koveke, E. P., Toda, K., and Eyre, B. D.: Dimethylsulfide (DMS) fluxes from permeable coral reef carbonate sediments, Marine Chemistry, 208, 1-10, https://doi.org/10.1016/j.marchem.2018.11.008, 2019.

Draxler, R. R. and Hess, G. D.: Description of the HYSPLIT_4 modeling system, Tech. rep., National Oceanic Atmospheric Administration, Silver Spring, Maryland, USA, 1997.

Draxler, R. R. and Hess, G. D.: An Overview of the HYSPLIT_4 Modelling System for Trajectories, Dispersion, and Deposition, Australian Meteorological Magazine, 47, 295-308, 1998.

Drewnick, F., Hings, S. S., DeCarlo, P., Jayne, J. T., Gonin, M., Fuhrer, K., Weimer, S., Jimenez, J. L., Demerjian, K. L., Borrmann, S., and Worsnop, D. R.: A new time-of-flight aerosol mass spectrometer (TOF-AMS) - Instrument description and first field deployment, Aerosol Science and Technology, 39, 637-658, https://doi.org/10.1080/02786820500182040, 2005.

Emmons, L. K., Walters, S., Hess, P. G., Lamarque, J.-F., Pfister, G. G., Fillmore, D., Granier, C., Guenther, A., Kinnison, D., Laepple, T., Orlando, J., Tie, X., Tyndall, G., Wiedinmyer, C., Baughcum, S. L., and Kloster, S.: Description and evaluation of the Model for Ozone and Related chemical Tracers, version 4 (MOZART-4), Geoscientific Model Development, 3, 43-67, https://doi.org/10.5194/gmd-3-43-2010, 2010.

European Commission Joint Research Centre and Netherlands Environmental Assessment Agency: Emission Database for Global Atmospheric Research (EDGAR), http://edgar.jrc.ec.europe.eu, 2012.

Fast, J. D., Gustafson, W. I., Easter, R. C., Zaveri, R. A., Barnard, J. C., Chapman, E. G., Grell, G. A., and Peckham, S. E.: Evolution of ozone, particulates, and aerosol direct radiative forcing in the vicinity of Houston using a fully coupled meteorology-chemistry-aerosol model, Journal of Geophysical Research Atmospheres, 111, 1-29, https://doi.org/10.1029/2005JD006721, 2006.

Fiddes, S. L., Woodhouse, M. T., Nicholls, Z., Lane, T. P., and Schofield, R.: Cloud, precipitation and radiation responses to large perturbations in global dimethyl sulfide, Atmospheric Chemistry and Physics, 18, 10 177-10 198, https://doi.org/10.5194/acp-18-10177-2018, 2018.

Fiddes, S. L., Woodhouse, M. T., Lane, T. P., and Schofield, R.: Coral reef-derived dimethyl sulfide and the climatic impact of the loss of coral reefs, Atmospheric Chemistry and Physics Discussions, 21, 5883-5903, https://doi.org/https://doi.org/10.5194/acp-2020-1054, 2021.

Fröhlich, R., Cubison, M. J., Slowik, J. G., Bukowiecki, N., Prévôt, A. S. H., Baltensperger, U., Schneider, J., Kimmel, J. R., Gonin, M., Rohner, U., Worsnop, D. R., and Jayne, J. T.: The ToF-ACSM: a portable aerosol chemical speciation monitor with TOFMS detection, Atmospheric Measurement Techniques, 6, 3225-3241, https://doi.org/10.5194/amt-6-3225-2013, 2013. 
Fuentes, E., Coe, H., Green, D., De Leeuw, G., and McFiggans, G.: On the impacts of phytoplankton-derived organic matter on the properties of the primary marine aerosol - Part 1: Source fluxes, Atmospheric Chemistry and Physics, 10, 9295-9317, https://doi.org/10.5194/acp10-9295-2010, 2010.

Gong, S. L., Barrie, L. A., and Blanchet, J.-P.: Modeling sea-salt aerosols in the atmosphere: 1. Model development, Journal of Geophysical Research: Atmospheres, 102, 3805-3818, https://doi.org/10.1029/96jd02953, 1997.

Green, T. K. and Hatton, A. D.: The Claw Hypothesis: A New Perspective on the Role of Biogenic Sulphur in the Regulation of Global Climate, Oceanography and Marine Biology, 52, 315-336, https://doi.org/10.1201/b17143-7, 2014.

Grell, G. A. and Dévényi, D.: A generalized approach to parameterizing convection combining ensemble and data assimilation techniques, Geophysical Research Letters, 29, 38-1, https://doi.org/10.1029/2002gl015311, 2002.

Guenther, A., Zimmerman, P., and Wildermuth, M.: Natural volatile organic compound emission rate estimates for U.S. woodland landscapes, Atmospheric Environment, 28, 1197-1210, https://doi.org/10.1016/1352-2310(94)90297-6, 1994.

Gustafson, W. I., Chapman, E. G., Ghan, S. J., Easter, R. C., and Fast, J. D.: Impact on modeled cloud characteristics due to simplified treatment of uniform cloud condensation nuclei during NEAQS 2004, Geophysical Research Letters, 34, 1-5, https://doi.org/10.1029/2007GL030021, 2007.

Hopkins, F. E., Bell, T. G., Yang, M., Suggett, D. J., and Steinke, M.: Air exposure of coral is a significant source of dimethylsulfide (DMS) to the atmosphere, Scientific Reports, 6, 36 031, https://doi.org/10.1038/srep36031, 2016.

Iacono, M. J., Delamere, J. S., Mlawer, E. J., Shephard, M. W., Clough, S. A., and Collins, W. D.: Radiative forcing by long-lived greenhouse gases: Calculations with the AER radiative transfer models, Journal of Geophysical Research Atmospheres, 113, 2-9, https://doi.org/10.1029/2008JD009944, 2008.

Jackson, R. L., Gabric, A., and Cropp, R.: Effects of ocean warming and coral bleaching on aerosol emissions in the Great Barrier Reef, Australia, Scientific Reports, 8, 1-11, https://doi.org/10.1038/s41598-018-32470-7, 2018.

610 Jackson, R. L., Gabric, A. J., Cropp, R., and Woodhouse, M. T.: Dimethylsulfide (DMS), marine biogenic aerosols and the ecophysiology of coral reefs, Biogeosciences, 17, 2181-2204, https://doi.org/10.5194/bg-17-2181-2020, 2020a.

Jackson, R. L., Gabric, A. J., Woodhouse, M. T., Swan, H. B., Jones, G. B., Cropp, R., and Deschaseaux, E. S.: Coral Reef Emissions of Atmospheric Dimethylsulfide and the Influence on Marine Aerosols in the Southern Great Barrier Reef, Australia, Journal of Geophysical Research: Atmospheres, 125, https://doi.org/10.1029/2019JD031837, 2020b.

Jacobson, M. Z., Turco, R. P., Jensen, E. J., and Toon, O. B.: Modeling coagulation among particles of different composition and size, Atmospheric Environment, 28, 1327-1338, https://doi.org/10.1016/1352-2310(94)90280-1, 1994.

Janjić, Z. I.: The Step-Mountain Eta Coordinate Model: Further Developments of the Convection, Viscous Sublayer, and Turbulence Closure Schemes, Monthly Weather Review, 122, 927-945, https://doi.org/10.1175/1520-0493(1994)122<0927:TSMECM>2.0.CO;2, 1994.

Janjic, Z. I.: The surface layer in the NCEP Eta Model,, in: Eleventh Conference on Numerical Weather Prediction, pp. 354-355, Amer. Meteor. Soc., Boston, MA,, Norfolk, VA, 1996.

Jayne, J. T., Leard, D. C., Zhang, X., Davidovits, P., Smith, K. A., Kolb, C. E., and Worsnop, D. R.: Development of an Aerosol Mass Spectrometer for Size and Composition Analysis of Submicron Particles, Aerosol Science and Technology, 33, 49-70, https://doi.org/10.1080/027868200410840, 2000.

Jones, G., Curran, M., Swan, H., and Deschaseaux, E.: Dimethylsulfide and Coral Bleaching: Links to Solar Radiation, Low Level Cloud and the Regulation of Seawater Temperatures and Climate in the Great Barrier Reef, American Journal of Climate Change, 06, 328-359, https://doi.org/10.4236/ajcc.2017.62017, 2017. 
Jones, G. B.: Coral animals combat stress with sulphur, Nature, 502, 634-635, https://doi.org/10.1038/nature12698, 2013.

Jones, G. B. and Trevena, A. J.: The influence of coral reefs on atmospheric dimethylsulphide over the Great Barrier Reef, Coral Sea, Gulf of Papua and Solomon and Bismarck Seas, Marine and Freshwater Research, 56, 85-93, https://doi.org/10.1071/MF04097, 2005. sulfoniopropionate in coral reef waters of the great barrier reef, Environmental Chemistry, 4, 310-322, https://doi.org/10.1071/EN06065, 2007.

Jung, E. and Shao, Y.: An intercomparison of four wet deposition schemes used in dust transport modeling, Global and Planetary Change, 52, 248-260, https://doi.org/10.1016/j.gloplacha.2006.02.008, 2006.

Kameyama, S., Tanimoto, H., Inomata, S., Tsunogai, U., Ooki, A., Yokouchi, Y., Takeda, S., Obata, H., and Uematsu, M.: Equilibrator inlet-proton transfer reaction-mass spectrometry (EI-PTR-MS) for sensitive, high-resolution measurement of dimethyl sulfide dissolved in seawater, Analytical Chemistry, 81, 9021-9026, https://doi.org/10.1021/ac901630h, 2009.

Kanaya, Y., Taketani, F., Komazaki, Y., Liu, X., Kondo, Y., Sahu, L. K., Irie, H., and Takashima, H.: Comparison of black carbon mass concentrations observed by multi-angle absorption photometer (MAAP) and continuous soot-monitoring system (COSMOS) on fukue Island and in Tokyo, Japan, Aerosol Science and Technology, 47, 1-10, https://doi.org/10.1080/02786826.2012.716551, 2013.

Kettle, A. J. and Andreae, M.: Flux of dimethylsulfide from the oceans : A comparison of updated data sets and flux models, Journal of Geophysical Research, 105, 793-26, https://doi.org/10.1029/2000JD900252, 2000.

Khan, M. A., Gillespie, S. M., Razis, B., Xiao, P., Davies-Coleman, M. T., Percival, C. J., Derwent, R. G., Dyke, J. M., Ghosh, M. V., Lee, E. P., and Shallcross, D. E.: A modelling study of the atmospheric chemistry of DMS using the global model, STOCHEM-CRI, Atmospheric Environment, 127, 69-79, https://doi.org/10.1016/j.atmosenv.2015.12.028, 2016.

Kloster, S., Feichter, J., Maier-Reimer, E., Six, K. D., Stier, P., and Wetzel, P.: DMS cycle in the marine ocean-atmosphere system \&amp;ndash; a global model study, Biogeosciences, 3, 29-51, https://doi.org/10.5194/bg-3-29-2006, 2006.

Korhonen, H., Carslaw, K. S., Spracklen, D. V., Mann, G. W., and Woodhouse, M. T.: Influence of oceanic dimethyl sulfide emissions on cloud condensation nuclei concentrations and seasonality over the remote Southern Hemisphere oceans: A global model study, Journal of Geophysical Research: Atmospheres, 113, 1-16, https://doi.org/10.1029/2007JD009718, 2008.

Ladwig, W.: wrf-python (Version 1.3.2), 2017.

Lana, A., Bell, T. G., Simó, R., Vallina, S. M., Ballabrera-Poy, J., Kettle, A. J., Dachs, J., Bopp, L., Saltzman, E. S., Stefels, J., Johnson, J. E., and Liss, P. S.: An updated climatology of surface dimethlysulfide concentrations and emission fluxes in the global ocean, Global Biogeochemical Cycles, 25, 1-17, https://doi.org/10.1029/2010GB003850, 2011.

Leahy, S. M., Kingsford, M. J., and Steinberg, C. R.: Do Clouds Save the Great Barrier Reef? Satellite Imagery Elucidates the Cloud-SST Relationship at the Local Scale, PLoS ONE, 8, e70 400, https://doi.org/10.1371/journal.pone.0070400, 2013.

Liss, P. S. and Merlivat, L.: Air-Sea Gas Exchange Rates: Introduction and Synthesis, in: The Role of Air-Sea Exchange in Geochemical Cycling, edited by Buat-Ménard, P., pp. 113-127, Springer Netherlands, Dordrecht, https://doi.org/10.1007/978-94-009-4738-2_5, 1986.

Liu, P. S. K., Deng, R., Smith, K. A., Williams, L. R., Jayne, J. T., Canagaratna, M. R., Moore, K., Onasch, T. B., Worsnop, D. R., and Deshler, T.: Transmission Efficiency of an Aerodynamic Focusing Lens System: Comparison of Model Calculations and Laboratory Measurements for the Aerodyne Aerosol Mass Spectrometer, Aerosol Science and Technology, 41, 721-733, https://doi.org/10.1080/02786820701422278, 2007. 
Longo, K. M., Freitas, S. R., Andreae, M. O., Setzer, A., Prins, E., and Artaxo, P.: The coupled aerosol and tracer transport model to the brazilian developments on the regional atmospheric modeling system (catt-brams)-part 2: Model sensitivity to the biomass burning inventories, Atmospheric Chemistry and Physics, 10, 5785-5795, https://doi.org/10.5194/acp-10-5785-2010, 2010.

Mahajan, A. S., Fadnavis, S., Thomas, M. a., Pozzoli, L., Gupta, S., Royer, S.-j., Saiz-Lopez, A., and Simó, R.: Quantifying the impacts of an updated global dimethyl sulfide climatology on cloud microphysics and aerosol radiative forcing, Journal of Geophysical Research: Atmospheres, 120, 2524-2536, https://doi.org/10.1002/2014JD022687, 2015.

McCormick, R. A. and Ludwig, J. H.: Climate Modification by Atmospheric Aerosols, Science, 156, 1358-1359, https://doi.org/10.1126/science.156.3780.1358, 1967.

Modini, R. L., Ristovski, Z. D., Johnson, G. R., He, C., Surawski, N., Morawska, L., Suni, T., and Kulmala, M.: New particle formation and growth at a remote, sub-tropical coastal location, Atmospheric Chemistry and Physics Discussions, 9, 12 101-12 139, https://doi.org/10.5194/acpd-9-12101-2009, 2009.

Morrison, H., Thompson, G., and Tatarskii, V.: Impact of Cloud Microphysics on the Development of Trailing Stratiform Precipitation in a Simulated Squall Line: Comparison of One- and Two-Moment Schemes, Monthly Weather Review, 137, 991-1007, https://doi.org/10.1175/2008mwr2556.1, 2008.

Muñiz-Unamunzaga, M., Borge, R., Sarwar, G., Gantt, B., de la Paz, D., Cuevas, C. A., and Saiz-Lopez, A.: The influence of ocean halogen and sulfur emissions in the air quality of a coastal megacity: The case of Los Angeles, Science of the Total Environment, 610-611, 1536-1545, https://doi.org/10.1016/j.scitotenv.2017.06.098, 2018.

Omori, Y., Tanimoto, H., Inomata, S., Kameyama, S., Takao, S., and Suzuki, K.: Evaluation of using unfiltered seawater for underway measurement of dimethyl sulfide in the ocean by online mass spectrometry, Limnology and Oceanography: Methods, 11, 549-560, https://doi.org/10.4319/lom.2013.11.549, 2013.

Omori, Y., Tanimoto, H., Inomata, S., Ikeda, K., Iwata, T., Kameyama, S., Uematsu, M., Gamo, T., Ogawa, H., and Furuya, K.: Sea-to-air flux of dimethyl sulfide in the South and North Pacific Ocean as measured by proton transfer reaction-mass spectrometry coupled with the gradient flux technique, Journal of Geophysical Research, 122, 7216-7231, https://doi.org/10.1002/2017JD026527, 2017.

Pincus, R. and Baker, M. B.: Effect of precipitation on the albedo susceptibility of clouds in the marine boundary layer, Nature, 372, 250-252, https://doi.org/10.1038/372250a0, 1994.

Saide, P. E., Spak, S. N., Carmichael, G. R., Mena-Carrasco, M. A., Yang, Q., Howell, S., Leon, D. C., Snider, J. R., Bandy, A. R., Collett, J. L., Benedict, K. B., De Szoeke, S. P., Hawkins, L. N., Allen, G., Crawford, I., Crosier, J., and Springston, S. R.: Evaluating WRFchem aerosol indirect effects in southeast pacific marine stratocumulus during VOCALS-REx, Atmospheric Chemistry and Physics, 12, 3045-3064, https://doi.org/10.5194/acp-12-3045-2012, 2012.

Shao, Y., Ishizuka, M., Mikami, M., and Leys, J. F.: Parameterization of size-resolved dust emission and validation with measurements, Journal of Geophysical Research Atmospheres, 116, 1-19, https://doi.org/10.1029/2010JD014527, 2011.

Simmel, M. and Wurzler, S.: Condensation and activation in sectional cloud microphysical models, Atmospheric Research, 80, 218-236, https://doi.org/10.1016/j.atmosres.2005.08.002, 2006.

Simpson, D., Guenther, A., Hewitt, C. N., and Steinbrecher, R.: Biogenic emissions in Europe: 1. Estimates and uncertainties, Journal of Geophysical Research, 100, 22 875, https://doi.org/10.1029/95JD02368, 1995.

Su, C.-H., Eizenberg, N., Steinle, P., Jakob, D., Fox-Hughes, P., White, C. J., Rennie, S., Franklin, C., Dharssi, I., and Zhu, H.: BARRA v1.0: The Bureau of Meteorology Atmospheric high-resolution Regional Reanalysis for Australia, Geoscientific Model Development Discussions, pp. 1-33, https://doi.org/10.5194/gmd-2018-277, 2018. 
Swan, H. B., Ivey, J. P., Jones, G. B., and Eyre, B. D.: The validation and measurement uncertainty of an automated gas chromatograph for marine studies of atmospheric dimethylsulfide, Analytical Methods, 7, 3893-3902, https://doi.org/10.1039/c5ay00269a, 2015.

Swan, H. B., Jones, G. B., Deschaseaux, E. S. M., and Eyre, B. D.: Coral reef origins of atmospheric dimethylsulfide at Heron Island, southern Great Barrier Reef, Australia, Biogeosciences, 14, 229-239, https://doi.org/https://doi.org/10.5194/bg-14-229-2017, 2017.

Thomas, M. A., Suntharalingam, P., Pozzoli, L., Rast, S., Devasthale, A., Kloster, S., Feichter, J., and Lenton, T. M.: Quantification of DMS aerosol-cloud-climate interactions using the ECHAM5-HAMMOZ model in a current climate scenario, Atmospheric Chemistry and Physics, 10, 7425-7438, https://doi.org/10.5194/acp-10-7425-2010, 2010.

Tie, X.: Effect of clouds on photolysis and oxidants in the troposphere, Journal of Geophysical Research, 108, https://doi.org/10.1029/2003jd003659, 2003.

710 Twomey, S.: Pollution and the Planetary Albedo, Atmospheric Environment, 8, 1251-1256, 1974.

Vallina, S. M., Simó, R., and Gassó, S.: What controls CCN seasonality in the Southern Ocean? A statistical analysis based on satellite-derived chlorophyll and $\mathrm{CCN}$ and model-estimated $\mathrm{OH}$ radical and rainfall, Global Biogeochemical Cycles, 20, 1-13, https://doi.org/10.1029/2005GB002597, 2006.

Vlahos, P. and Monahan, E. C.: A generalized model for the air-sea transfer of dimethyl sulfide at high wind speeds, Geophysical Research Letters, 36, L21 605, https://doi.org/10.1029/2009GL040695, 2009.

Warner, J.: A Reduction in Rainfall Associated with Smoke from Sugar-Cane Fires-An Inadvertent Weather Modification?, Journal of Applied Meteorology, 7, 247-251, https://doi.org/10.1175/1520-0450(1968)007<0247:ARIRAW>2.0.CO;2, 1968.

Wexler, A. S., Lurmann, F. W., and Seinfeld, J. H.: Modelling urban and regional aerosols-I. model development, Atmospheric Environment, 28, 531-546, https://doi.org/10.1016/1352-2310(94)90129-5, 1994.

Wilks, D. S.: Statistical Methods in the Atmospheric Sciences, Elsevier, 3rd edn., https://doi.org/10.1016/B978-0-12-385022-5.00026-9, 2011.

Xu, K.-M. and Randall, D. A.: A Semiempirical Cloudiness Parameterization for Use in Climate Models, Journal of the Atmospheric Sciences, 53, 3084-3102, https://doi.org/10.1175/1520-0469(1996)053<3084:ASCPFU>2.0.CO;2, 1996.

Yang, Q., Fast, J. D., Wang, H., Easter, R. C., Morrison, H., Lee, Y.-N., Chapman, E. G., Spak, S. N., and Mena-Carrasco, M. A.: Assessing regional scale predictions of aerosols, marine stratocumulus, and their interactions during VOCALS-REx using WRF-Chem, Atmospheric Chemistry and Physics, 11, 11 951-11 975, https://doi.org/10.5194/acp-11-11951-2011, 2011.

Yu, S., Eder, B., Dennis, R., Chu, S.-H., and Schwartz, S. E.: New unbiased symmetric metrics for evaluation of air quality models, Atmospheric Science Letters, 7, 26-34, https://doi.org/10.1002/asl.125, 2006.

Zaveri, R. A.: Development and Evaluation of a Comprehensive Tropospheric Chemistry Model for Regional and Global Applications Development and Evaluation of a Comprehensive Tropospheric Chemistry Model for Regional and Global Applications, Ph.D. thesis, Virginia Polytechnic Institute and State University, http://scholar.lib.vt.edu/theses/available/etd-7197-18361/, 1997.

Zaveri, R. A., Easter, R. C., Fast, J. D., and Peters, L. K.: Model for Simulating Aerosol Interactions and Chemistry (MOSAIC), Journal of Geophysical Research Atmospheres, 113, 1-29, https://doi.org/10.1029/2007JD008782, 2008. 


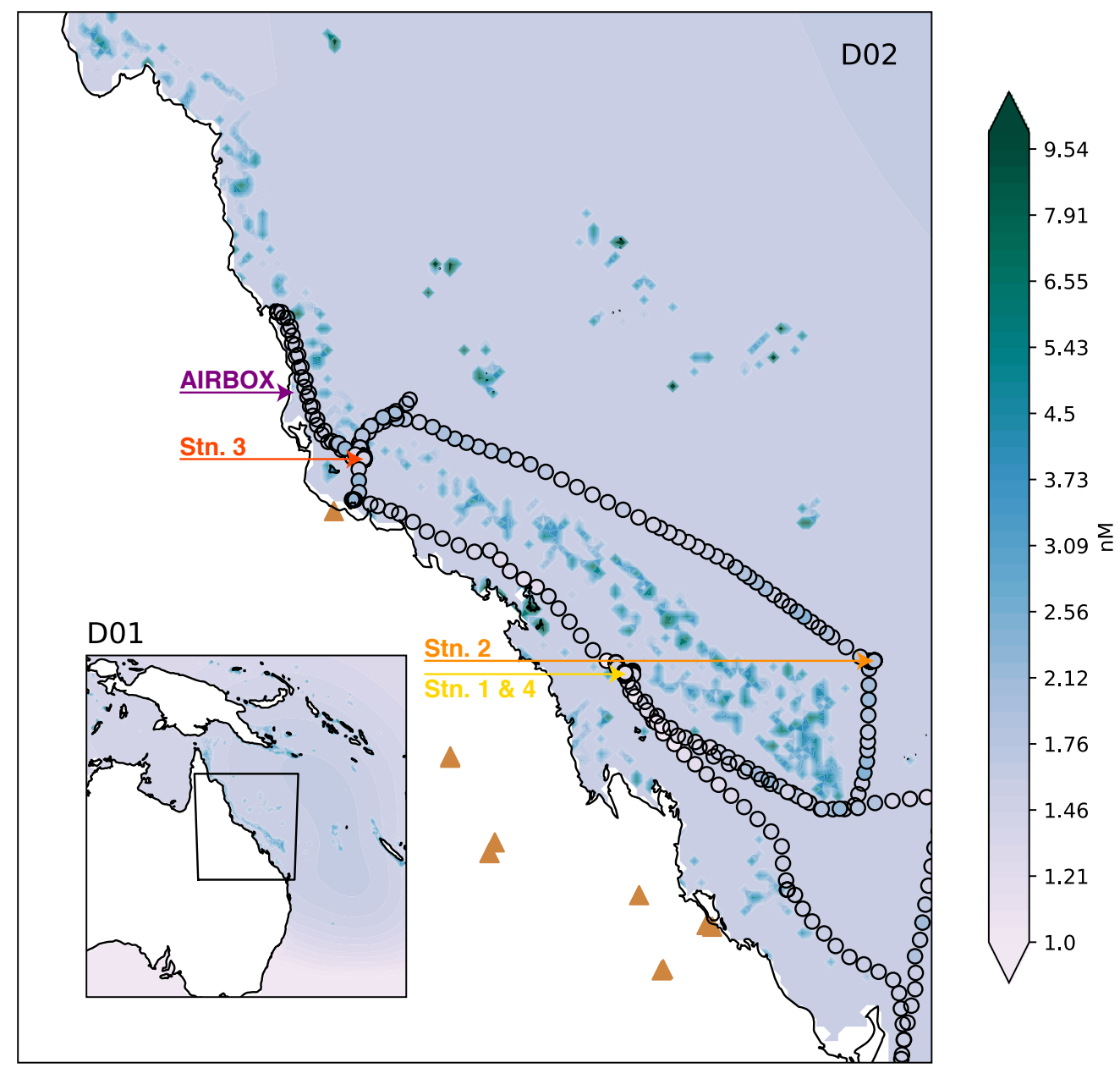

Figure 1. Domain two (D02) of the WRF-Chem simulations, with the outer domain (D01) inset. The colours represent the DMS surface water concentrations for the simulations including coral reef-derived DMS (note the log scale). The RVI ship track is shown by black outlined circles, also coloured by DMS observations. The locations of the RVI stations and AIRBOX are shown by coloured text and arrows. The brown triangles indicate where fossil fuel or biomass burning power generators are located 

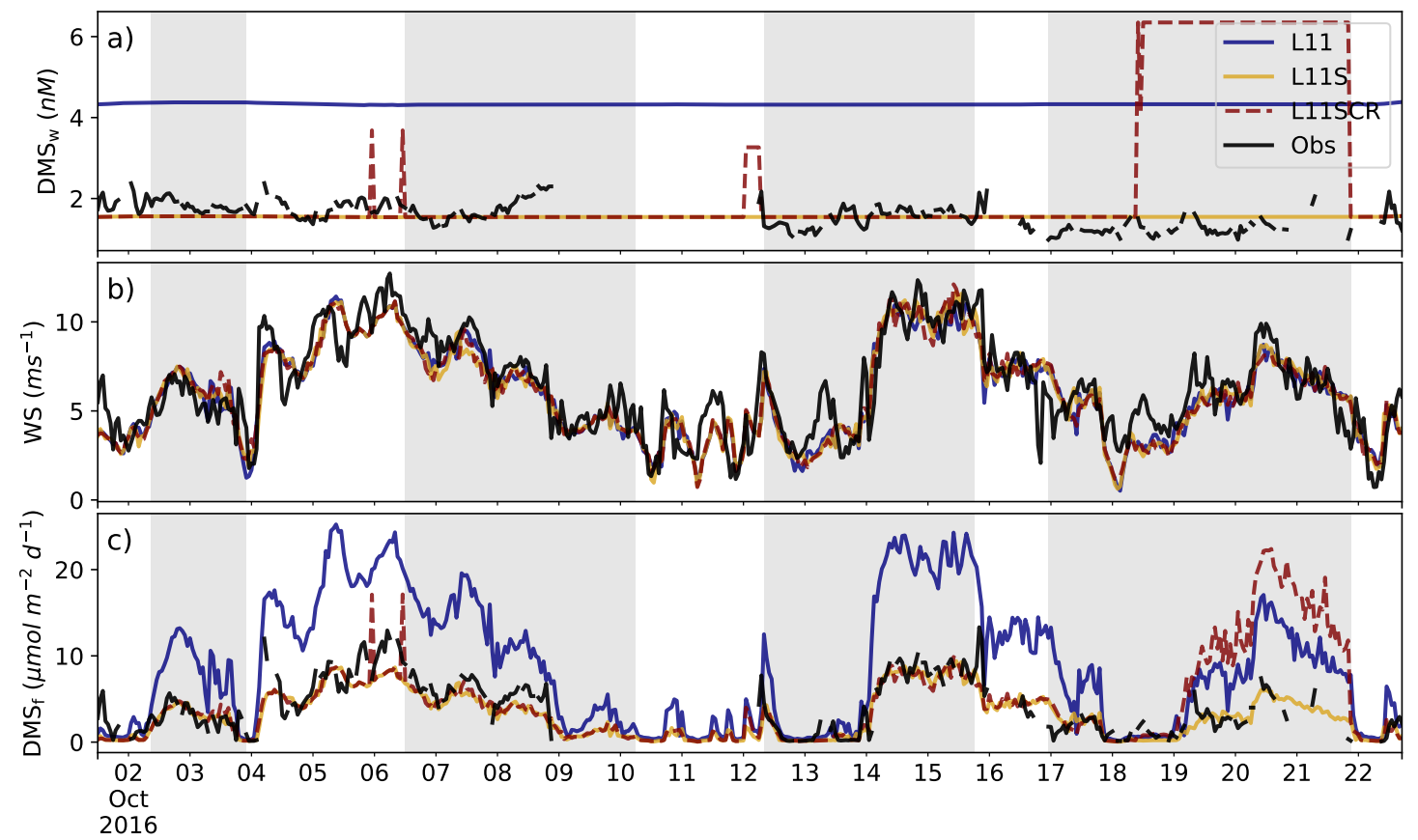

Figure 2. RVI observations (black) and model estimates (coloured) of a) $\operatorname{DMS}_{w}(\mathrm{nM})$, b) wind $\operatorname{speed}\left(\mathrm{ms}^{-1}\right)$ and c) the flux $D M S$ $\left(\mu \mathrm{molm}^{-2}\right.$ day $\left.^{-1}\right)$. Note the flux $D M S$ is calculated from observations using the Liss and Merlivat (1986) parameterisation. The three WRF-Chem simulations are L11 (blue), L11S (yellow) and L11SCR (red, dashed). They grey shading from left to right indicates when the ship was at station locations $2,3.1,3.2$ and 4 . 

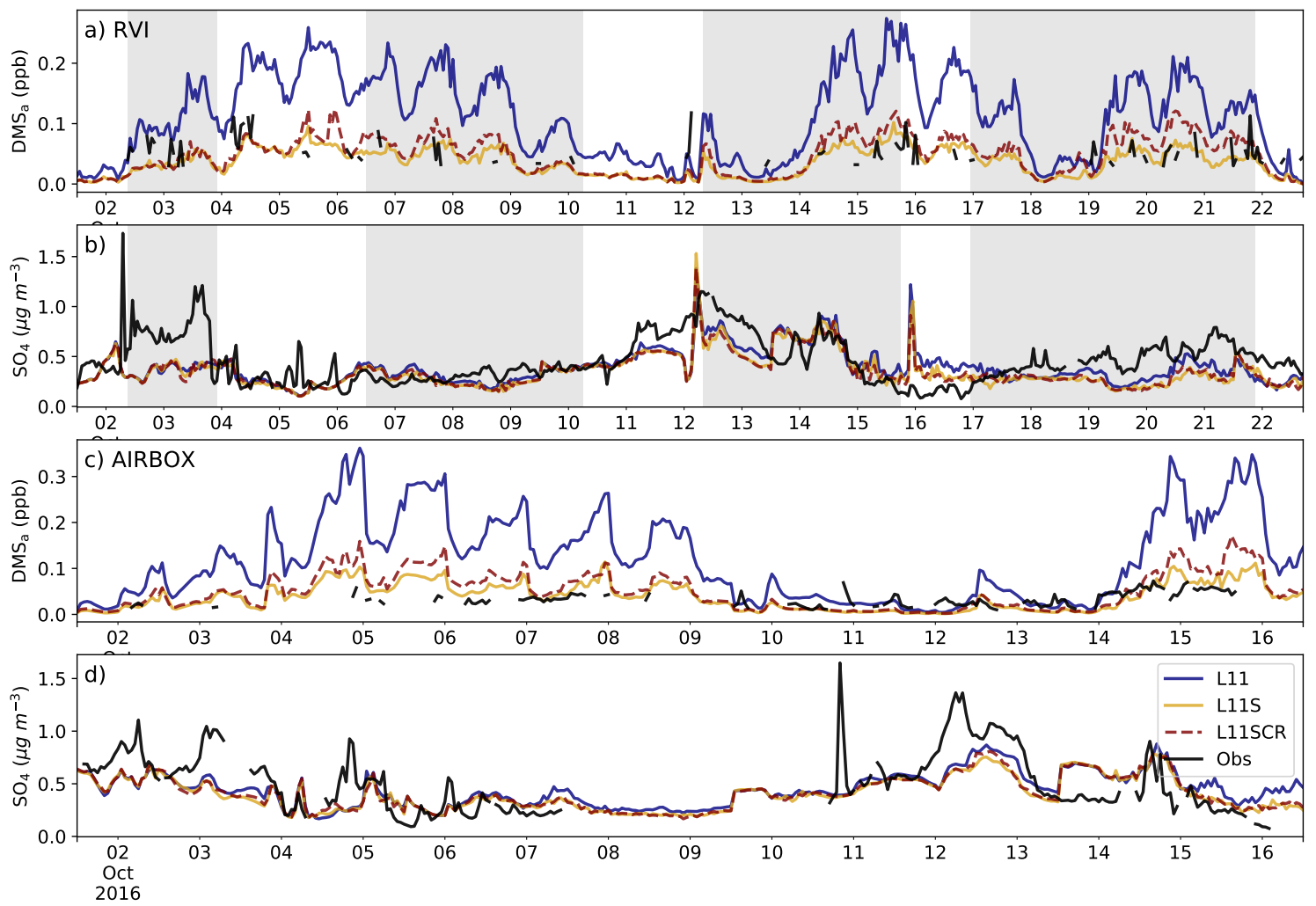

Figure 3. Observations (black) from the RVI (a,b) and AIRBOX (c,d) and corresponding model estimates (coloured) of a \& c) DMS $a$ (ppb), b \& d) $\mathrm{SO}_{4}{ }^{2-}$ aerosol mass $\left(\mu \mathrm{g} \mathrm{cm}^{-3}\right.$ ). The three WRF-Chem simulations are L11 (blue), L11S (yellow) and L11SCR (red, dashed). They grey shading from left to right indicates when the ship was at station locations 2, 3.1, 3.2 and 4 . Note that the dates in a, b and c, $d$ are not the same. 

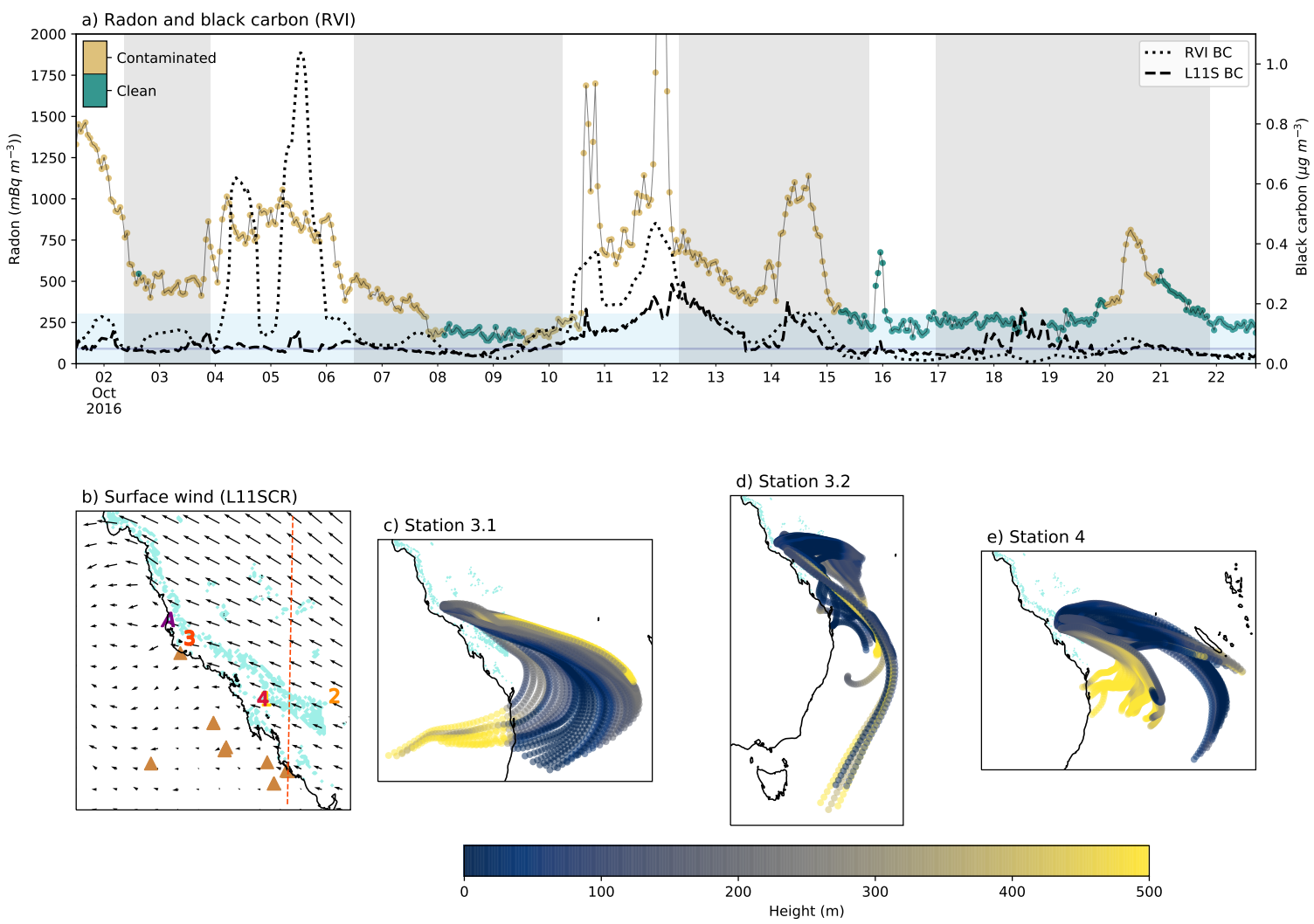

Figure 4. a) Radon concentrations from the RVI and coloured by the ship exhaust flag (left axis). Black carbon concentrations (right axis) from the RVI (dotted line) and L11S (dashed line). The light blue shading indicates when radon was below $300 \mathrm{mBq}^{-3}$ and the dark blue line indicates black carbon below $0.05 \mu \mathrm{g} \mathrm{m}^{-3}$. The grey shading represents ship stations 2, 3.1, 3.2 and 4. b) the surface winds from L11SCR. Coral reefs are shown in light blue. Numbers indicate RVI observation stations 1-4 coloured yellow through to red and the purple A indicates the AIRBOX location. The brown triangles indicate where fossil fuel power generators are located and the dashed orange vertical line indicates where a transect was taken for vertical profile analysis. c-e) HYSPLIT back trajectories for every two hours while the ship was at station 3.1, 3.2 and 4 respectively, coloured by height. 

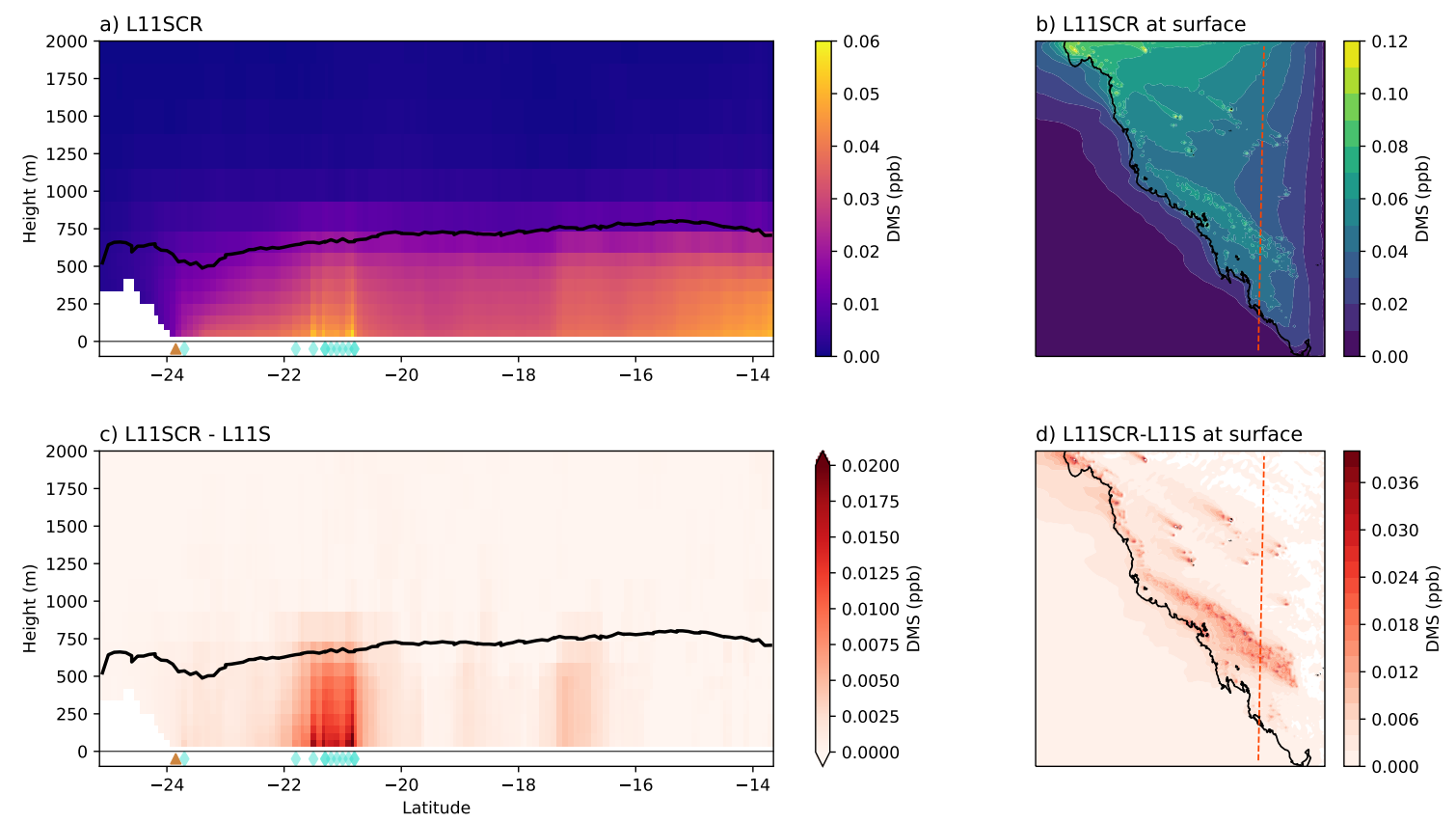

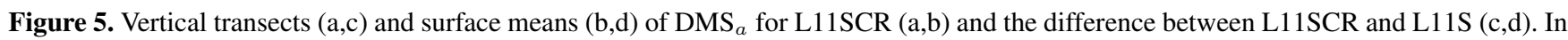
a and $\mathrm{c}$ the black line indicates the mean boundary layer height, while the brown triangle shows the location of the Gladstone power station and the blue diamonds show grid points within which coral reefs are found. 
https://doi.org/10.5194/acp-2021-507

Preprint. Discussion started: 29 July 2021

(c) Author(s) 2021. CC BY 4.0 License.
Atmospheric

Chemistry and Physics

Discussions
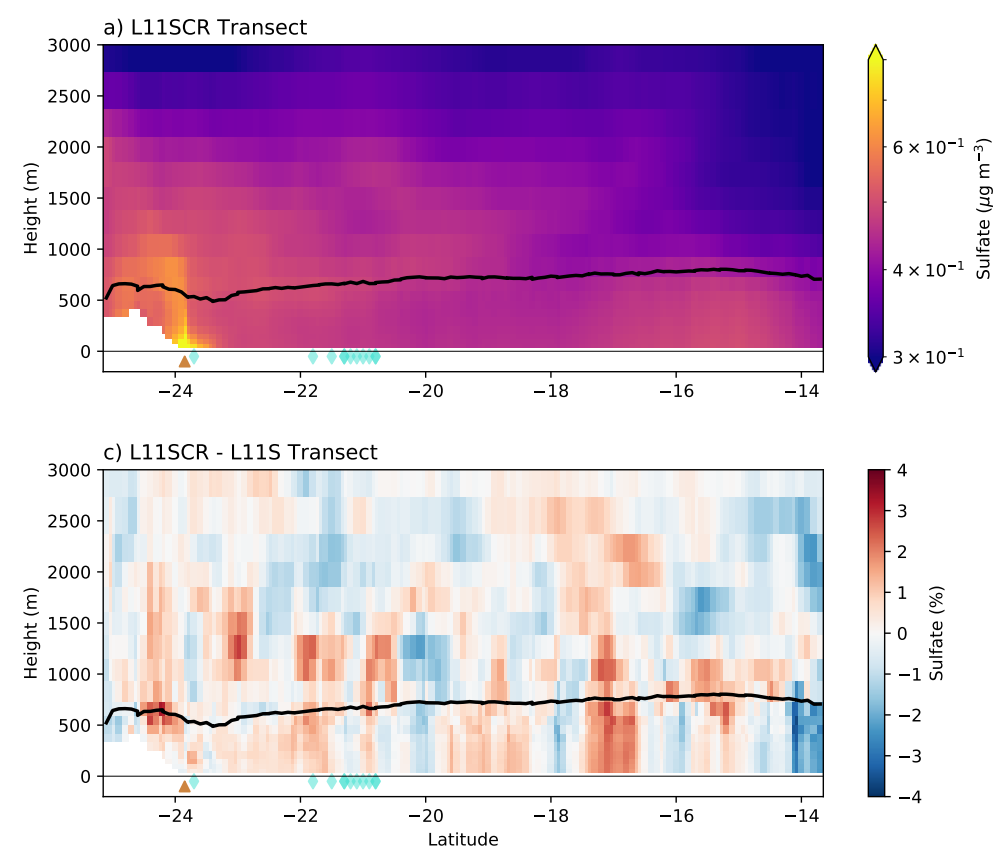
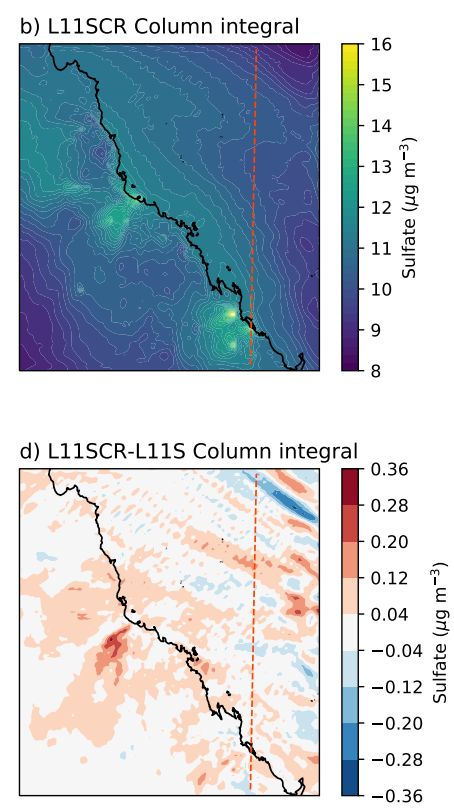

Figure 6. As for Figure 5 but for total sulfate aerosol mass. 

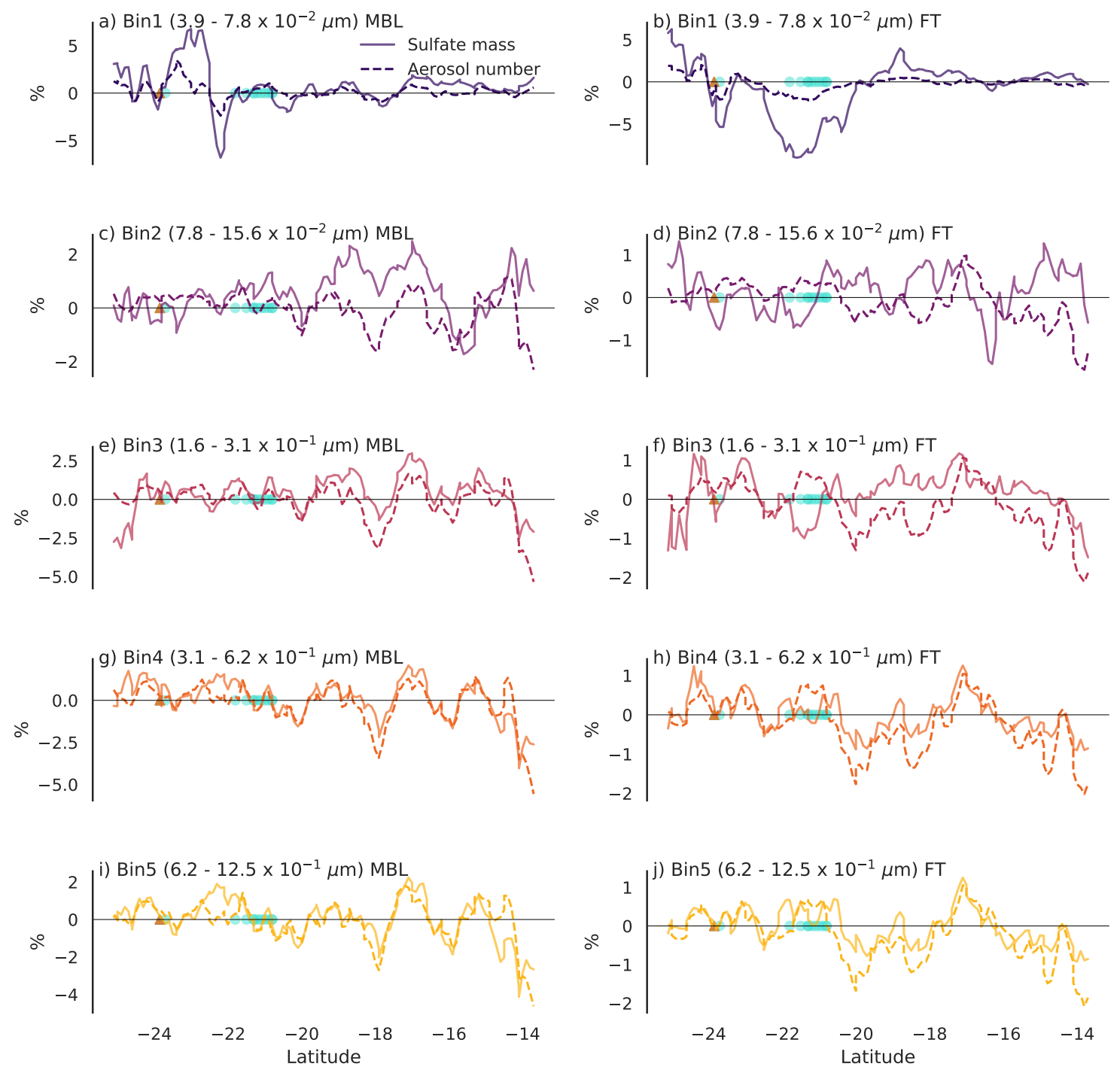

Figure 7. Percentage changes (L11SCR-L11S) along the vertical transect of total boundary layer column (left) and free troposphere column (right) sulfate mass (solid line) and total aerosol number (dashed line) for the five smallest bin sizes representing the Aitken mode (bin 1) and accumulation mode (bins 2-5). The brown triangle shows the location of the Gladstone power station and the blue diamonds show grid points within which coral reefs are found. 